VILA VIÑAS, D., «Sociedad del riesgo y crisis económica en España. Análisis de la vigencia del enfoque de 'la sociedad del riesgo' respecto a los regímenes emergentes en el tratamiento de la incertidumbre», REDUR Io, diciembre 2012 , págs. 207-24I. ISSN i695-078X

\title{
SOCIEDAD DEL RIESGOY CRISIS ECONÓMICA EN ESPAÑA. ANÁLISIS DE LA VIGENCIA DEL ENFOQUE DE «LA SOCIEDAD DEL RIESGO» RESPECTO A LOS REGÍMENES EMERGENTES EN EL TRATAMIENTO DE LA INCERTIDUMBRE
}

\author{
David VILA VIÑAS \\ DOCTOR EN DERECHO \\ INVESTIGADOR DEL LABORATORIO DE SOCIOLOGÍA JURÍDICA \\ DE LA UNIVERSIDAD DE ZARAGOZA
}

\begin{abstract}
SUMARIO: I. Introducción. II. La formación de una actividad de gestión de la incertidumbre. II.I. De la sociedad del riesgo a la seguridad. II.2. Formación de dispositivos de previsión durante la modernidad. III. Algunas tendencias contemporáneas en el gobierno de la incertidumbre a través del riesgo. IV. La gestión de la crisis económica de 2008 desde la perspectiva de la regulación del riesgo. IV.r. La sociedad del riesgo para el análisis de los cambios en la gestión de la incertidumbre: límites de la intuición. IV.2. Sociedad del riesgo y sociedad del crecimiento. IV.3. Nueva gobernabilidad postworkfarista: incertidumbre y riesgo sin crecimiento ni empleo. IV.4. Situación de las poblaciones vulnerables en el marco de la nueva gobernabilidad. V. Conclusión: hacia nuevos regímenes de regulación del riesgo. VI. Referencias bibliográficas.
\end{abstract}

RESUMEN: Este artículo pretende analizar de manera crítica la perspectiva de la «sociedad de riesgo» a la luz de los enfoques post-foucualtianos elaborados desde los años I990. Se pretende esbozar así un marco analítico en que las categorías de riesgo, incertidumbre, seguridad, políticas públicas y derecho puedan responder a las transformaciones que los Estados del Sur de Europa están viviendo en la estela de la crisis financiera global de 2008.A través del análisis de las políticas sociales recientes en España, se realizará una aproximación a los nuevos regímenes de regulación de riesgos en los ámbitos de la regulación pública y por parte de los individuos y familias.

PALABRAS CLAVE: riesgo, gobernabilidad, política social, crisis, Estado.

ABSTRACT: This article aims to adress in a critical way the perspective of the «risk society» within the post-foucauldian frameworks elaborated since the I990s. The main objective is the proposition of an analytical framework where the notions of risk, uncertainty, security, public policy and law are able to answer to the transformation happened in the Southern States of Europe since the 2008 economic crises. Through the analysis of the recent Spanish social policies, it's done an approach to the new regimes of regulation of risks in the matter of public regulation and from the individuals and families.

KEYWORDS: risk, governance, social policy, crisis, State. 


\section{Introducción}

Como resulta visible en los actuales discursos de gobierno, son frecuentes las apelaciones a la inseguridad, al riesgo y a la prevención. Sin embargo, queda mucho menos claro el rol que estas nociones desempeñan en el diseño e implementación de las políticas públicas en nuestro entorno.A este respecto, hemos diferenciado el tratamiento del riesgo en dos grandes ámbitos sociales, que mantienen continuidades muy relevantes que buscaremos subrayar, pero que implican racionalidades políticas y medios de intervención muy distintos. Por un lado, la cuestión del riesgo tiene una vertiente más material y social, que es la que más interesa aquí, mientras que también conserva una vertiente penal y de defensa social ${ }^{\mathrm{I}}$.En cualquier caso, el objetivo sigue siendo alcanzar cierta profundidad en el análisis de las implicaciones de tales categorías para las políticas públicas implementadas en España desde 20 Io.

Con este objeto, realizaremos un doble movimiento conceptual. De un lado, transitaremos desde una noción generalizada de riesgo hacia una noción más concreta, histórica e inscrita en los juegos de saber-poder, propios de los enfoques foucaultianos. De otro lado, presentaremos, respecto a las perspectivas que ponen sobre la mesa una pluralidad de problemas en términos de riesgos, incertidumbres e inseguridades, una problematización de la seguridad menos aislada y articulada en el marco teórico de la gobernabilidad.

En las dos últimas décadas, la llamada sociedad del riesgo se ha convertido en una descripción recurrente de nuestras sociedades, aunque sobre esta idea se hayan formulado diferentes visiones. La de mayor impacto, se vertebra en torno a la influencia de los conocidos trabajos de Ulrich Beck $^{2} \mathrm{y}$, salvando las respectivas diferencias, de NiklasLuhmann 3 o de Anthony Giddens ${ }^{4}$. Ésta conceptúa la sociedad del riesgo como una fase evolutiva de la modernidad, donde el riesgo es una característica objetiva de lo humano, acrecentada en el actual estadio de modernización hasta constituirse en una cuestión política fundamental, susceptible de afectar de manera decisiva a nuestra identidad y a nuestra existencia. En contraste con ella, las nociones apuntadas desde perspectivas postfoucaultianas inscriben las nociones de riesgo dentro de unas tecnologías de gobierno, sin aludir a su veracidad sustancial, sino incidiendo en su funcionalidad dentro de todo un haz de estrategias de cálculo, de diagnósticos e intervenciones sobre las prácticas humanas.

Dado que nuestro enfoque parte del contraste con la perspectiva dominante de la sociedad de riesgo, conviene ampliar estas explicaciones ${ }^{5}$. Desde las perspectivas más objetivas, los riesgos se definirían como «sucesos o peligros reales en relación con los que podemos hacer aproximaciones objetivas sin resultar confundidos por factores subjetivos o

${ }^{I}$ Vid. VILA VIÑAS, D. El gobierno de la infancia. Análisis socio-jurídico del control $y$ de las políticas de infancia contemporáneas. Tesis doctoral. Univ. de Zaragoza, 20I2; donde el capítulo cuarto está dedicado a tal cuestión.

${ }^{2}$ BECK, U. La sociedad del riesgo: hacia una nueva modernidad (J. Navarro, D. Jiménez y M. R. Borrás, trads.), $\mathrm{I}^{\mathrm{a}}$ edición en col. Surcos, Barcelona, Paidós, 2006.

${ }^{3}$ LUHMANN, N. Risk: a sociological theory (R. Barrett, trans.), $\mathrm{I}^{\mathrm{a}}$ edición en ingles, New York, Aldine de Gruyter, I993.

${ }^{4}$ GIDDENS, A. Consecuencias de la modernidad (A. Lizón, trad.), ra edición en castellano, Madrid, Alianza, I999.

${ }_{5}$ ZINN, J. O. Social theories of risk and uncertainty: an introduction. $\mathrm{I}^{\mathrm{a}}$ edición, Malden, MA, Blackwell, 2008. (págs. 5-I4), realiza una integración muy útil de diferentes enfoques teóricos que subrayan dimensiones complementarias de la sociedad de riesgo. En este sentido, GARLAND, D. (2003) «The rise of risk», Risk and morality, en R. V. Ericson \& A. Doyle (eds.), Toronto, University of Toronto Press, 2003, p. 48-86.(págs. 50-6I), también realiza una caracterización general de la cuestión de riesgo bastante abierta, que marca ciertas distancias respecto a las de Beck y Giddens. 
sociales» ${ }^{6}$. Sin embargo, estos elementos subjetivos y sociales pronto se incorporaron al análisis de las políticas de prevención de riesgos7.

Pese a estas variaciones, podemos identificar algunos rasgos comunes en las caracterizaciones más difundidas de las sociedades del riesgo. En primer lugar, su impacto generalizado sobre todo el cuerpo social y su cotidianeidad, ligados a las tendencias globalizadoras propias de la evolución del proceso de modernización-industrialización, como una suerte de complejo de efectos negativos o problemas asociados a esta expansión. Si bien es cierto que dicha visión, tomada cuenta de que hacía abstracción de distintas desigualdades sociales y particularidades de este proceso $^{8}$, se ha visto muy matizada después ${ }^{9}$.

En segundo lugar, destaca la gradualidad de esta categoría de riesgo y una tendencia a su individualización o a la responsabilización individual ante su advenimiento. Otros autores, como Bauman ${ }^{\mathrm{Io}}$, también destacan que los cambios sociales que componen la llamada «modernidad líquida» se estructuran de forma que deben ser soportados por los propios sujetos implicados, definidos como «electores libres» que deben soportar así «las consecuencias de sus elecciones». A su vez, es obvio que estas perspectivas que aquí agrupamos por razones prácticas no tienen una completa homogeneidad y que el desarrollo de sus distintos aspectos ha sido desigual o ha vivido elusiones teóricas ${ }^{\text {II }}$ o contextuales respecto a un ámbito sureuropeo ${ }^{\mathrm{I} 2}$.

En cualquier caso, para la literatura post-foucaultiana, la cuestión es bien distinta. De una parte, ha descartado la existencia del riesgo como una realidad, para afirmarlo como un saber, como una forma de ordenar y de transformar las cuestiones referidas a la incertidumbre social en cuestiones calculables y, por tanto, susceptibles de encaje en una determinada gubermentalidad, basada asimismo sobre el cálculo de las conductas de los individuos, los grupos y las poblaciones ${ }^{\mathrm{r} 3}$.

Ello es coherente con el giro foucaultiano, concentrado en la descripción de las condiciones de validación de los saberes y las prácticas de gobierno. En el marco de la gobernabilidad $^{\mathrm{I}}$, las intervenciones realizadas para influir sobre las posibilidades de acción

${ }^{6}$ Zinn, Social theories of risk and uncertainty: an introduction, cit., págs. 4-5.

7 HOOD, C., ROTHSTEIN, H. y BALDWIN, R. El gobierno del riesgo: aproximación a los regímenes de regulación de riesgos, (J. Giménez Payrató, trad.), $2^{\mathrm{a}}$ reimpresión a la $\mathrm{I}^{\mathrm{a}}$ edición en castellano, Barcelona, Ariel, 2006. (pág. I9).

${ }^{8}$ Beck, La sociedad del riesgo: hacia una nueva modernidad, cit., págs. 45 ss.

9 Por ejemplo, la matización es clara aquí, al abrir procesos de conflictividad en la valoración, la producción y la distribución de estos riesgos: «En la modernidad avanzada, la producción social de riqueza va acompañada sistemáticamente por la producción social de riesgos. Por tanto, los problemas y conflictos de reparto de la sociedad de la carencia son sustituidos por los problemas y conflictos que surgen de la producción, definición y reparto de los riesgos producidos de manera científico-técnica» (Beck, La sociedad del riesgo: hacia una nueva modernidad, cit., pág. 25).

${ }^{\circ}$ BAUMAN, Z. Tiempos líquidos: vivir en una época de incertidumbre (C. Corral, trad.), Iª edición, Barcelona. Tusquets, 2007 (pág. II).

IPRIETO NAVARRO, E. «Sobre los límites y posibilidades de respuesta jurídica al riesgo», La seguridad en la sociedad del riesgo: un debate abierto, en C. Da Agra, J. L. Domínguez, J. A. García, P. Hebberecht y A. Recasens (eds.), Barcelona, Atelier, 2003, p. 27-46 (pág. 29).

${ }^{\text {I2}}$ RECASENS, «Globalización, riesgo y seguridad: el continuóse de lo que alguien empezóse», La seguridad en la sociedad del riesgo: un debate abierto, en C. Da Agra, J. L. Domínguez, J. A. García, P. Hebberecht y A. Recasens (eds.), Barcelona, Atelier, 2003, p. 365-379 e ídem; A. La seguridad y sus políticas. I ${ }^{\mathrm{a}}$ edición, Barcelona, Atelier, 2007.

${ }^{13}$ DEAN, M. Governmentality: power and rule in modern society, Ia reimpresión, London, etc., Sage, 2003 (págs. I77-I79). Asimismo, EWALD, F. «Insurance and risk», The Foucault effect: studies in governmentality, en G. Burchell, C. Gordon y P. Miller (eds.), London, Harvester Weatsheaf, I99I, p. I97-2IO.

${ }^{14}$ Puede verse una aproximación inicial al marco de la gobernabilidad en el conocido resumen del curso impartido por Foucault en I977-I978 «Seguridad, territorio, población» [FOUCAULT, M. «La gubermentalidad. 
de los otros están muy ligadas al saber producido sobre esas cuestiones. Es decir, no existe un ámbito de gobierno dado sobre el que se interviene, sino que ese campo (por ejemplo, la cuestión social y, en particular, el problema de la pobreza en las ciudades) debe ser configurado de antemano a través de distintas tecnologías de saber, como clásicamente han sido la estadística o las ciencias de la conducta.

Con carácter previo a esta actividad de saber, lo que existen son incertidumbres aleatorias o vicisitudes que no se pueden calcular, prever o prevenir. Después de tal actividad, resulta factible definir ciertos riesgos, establecer su incidencia y las regulaciones que la reduzcan o mitiguen sus efectos. Por ejemplo, en el liberalismo, la economía política liberal y el funcionamiento de su mercado aparecieron como criterios prioritarios de verificación y cálculo de las dinámicas que pueden ponerlos en riesgo. Correlativamente, el contenido material de la seguridad y qué haya que hacer para mantenerla remite a la contención de los riesgos de esas dinámicas.

Por tanto, una racionalización en función de las nociones de riesgo favorece la gestión desde una perspectiva de gobierno, a la vez que el régimen de esa racionalización (las nociones de riesgo) está producido durante el proceso de gubermentalización y gestión concreta de la incertidumbre; lo que no implica que todo provenga de una misma racionalidad monolítica en evolución. Esta manera particular en que determinadas sociedades (o algunos grupos) colocan un cierto aspecto de la realidaden la primera línea de sus asuntos políticos o éticos, de modo un tanto inédito, es lo que Foucault (1987, I3) denomina «problematización», actividad decisiva del pensamiento y después en la acción de gobierno.

Ewald ${ }^{15}$ trasladó este esquema al ámbito de los seguros: «como podría haber dicho Kant, la categoría de riesgo es una categoría del entendimiento; no puede ser dada por la sensibilidad o la intuición. Como tecnología de riesgo, los seguros son sobre todo un esquema de racionalidad, una manera de descomponer, cambiar, ordenar ciertos elementos de la realidad». Desde esta perspectiva, un estudio crítico y genealógico del riesgo debería investigar qué tecnología moral y política constituye su contexto, qué modos de cálculo, qué regímenes de prácticas o qué programas políticos y políticas sociales lo desarrollan y qué técnicas se inspiran en él. De nuevo, lo interesante, desde esta analítica del gobierno, no es el riesgo en sí, sino las formas de conocimiento que lo hacen pensable, calculable, comunicable, etc ${ }^{\mathrm{t}}$.

Así, estos enfoques se alejarían de la caracterización hegemónica en razón de un doble exceso del enfoque de la sociedad del riesgo. En primer lugar, exceso de generalidad. Aunque tal perspectiva tiene el mérito de avanzar caracterizaciones positivas de las sociedades postindustriales,la evolución de la modernidad se describe en términos demasiado amplios y comprensivos, que subrayan una linealidad histórica ${ }^{17}$. Ello va en detrimento de las distintas configuraciones epistémicas, paradojas y contradicciones políticas que componen el proceso

Resumen del curso del Colegio de Francia (I978) «Seguridad, territorio y población»», Obras esenciales. Estética, ética y hermenéutica, en Á. Gabilondo (ed.) (Á. Gabilondo, trad.), Barcelona, Paidós, I999, p. I75-I97]. Sin embargo, para un acercamiento algo más completo a este marco de pensamiento y acción de gobierno es imprescindible, al menos, acceder al curso completo [ídem; Seguridad, territorio, población. Curso del Collège de France (I977-I978), Senellart M., Fontana A. y Ewald F. (eds.), I edición en castellano, (H. Pons, trad.), Madrid, Akal, 2008.] y al impartido en el siguiente ejercicio [ídem; Nacimiento de la biopolítica. Curso en el Collège de France (1978-1979). Senellart M., Fontana A. y Ewald F. (eds.), I edición en castellano, (H. Pons, trad.), México, etc., Fondo de Cultura Económica, 2007.], amén de alguna conferencia especialmente clara al respecto [ídem; «Omnes et singulatum» Tecnologías del yo. Y otros textos afines, en M. Morey (ed.) (M. Morey, trad.), Barcelona, Paidós, I99I, p. 95-I40; entre otras].

${ }^{15}$ Ewald, Insurance and risk, cit., pág. I99.

${ }^{16}$ Dean, M., Governmentality: power and rule in modern society, cit. págs. I78-9.

${ }^{17}$ O’MALLEY, P. Risk, uncertainty and government, Ia edición, London, GlassHouse, 2004.(pág. 2). 
de modernización y del heterogéneo establecimiento de dispositivos de previsión y gestión de la incertidumbre ${ }^{\mathrm{I}}$.

En segundo lugar, exceso sustancial de la noción de riesgo, que abarca todas las esferas de la vida. Respecto a ésta, es preferible una noción que subraye la entidad de un determinado riesgo sobre un conjunto de prácticas situado ${ }^{19}$. Dado el carácter predominantemente práctico de las tecnologías de saber y los discursos de gobierno, análisis genealógicos más precisos han mostrado la variedad con que los riesgos se han configurado y funcionan en cada campo

En cualquier caso, si proponemos una versión de la sociedad del riesgo en esta clave post-foucaultiana, es porque entendemos que ello puede aclarar la configuración de la seguridad en las actuales gobernabilidades (neo)liberales. Particularmente en ellas, no existe una pura oposición entre seguridad y modernización libera ${ }^{20}$, sino una circulación por la que la producción de libertad y desregulación, bajo determinadas condiciones de formalización y control de sus riesgos, es condición de la seguridad, de la «buena marcha de los mercados». La crisis de 2008, que no es difícil entender como una crisis de la gobernabilidad neoliberal vigente desde los años i980s, ha modificado estos mecanismos dando un nuevo papel en los procesos económicos y sociales a las dinámicas de riesgo y de incertidumbre. Así, al hilo del despliegue que esta gobernabilidad neoliberal del riesgo tuvo en el contexto español, podremos examinar estos cambios así como sus efectos iniciales sobre ciertas poblaciones.

\section{La formación de una actividad de gestión de la incertidumbre}

En la primera parte de este artículo, analizaremos algunos elementos de la configuración del amplio problema de la seguridad como asunto central de la actividad de gobierno, así como de algunos pares modernos de problematización-solución, a fin de poder abordar después ciertas tendencias contemporáneas. Sin embargo, sin agotar esta cuestión, nos centraremos en la vertiente más socialy material de la seguridad, dejando para otra oportunidad la delimitación de su vertiente más penal; si bien, es evidente que las pasarelas, continuidades y rupturas entre ambas exigen que sobrevuele el trabajo un tratamiento inclusivo de la cuestión de la seguridad.

\section{II.I. De la sociedad del riesgo a la seguridad}

Más allá de la relativa novedad de estos paradigmas, la previsión ante la incertidumbre, y por tanto, la predicción, han sido tareas fundamentales del gobierno. El Estado, como agente principal del proceso de gubermentalización, con cuya evolución se ha ligado de manera intensa, había ido constituyendo y después asumiendo entre sus atribuciones y justificaciones, una serie de objetos políticos que, mucho más allá de los objetos tradicionales de intervención del soberano, aludían a la vida misma y a las necesidades de la población.

\footnotetext{
${ }^{18}$ Por ejemplo, en la lectura de estos enfoques, HUNT, A. «Risk and moralization in everyday life», Risk and morality, en R. V. Ericson \& A. Doyle (eds.), Toronto: University of Toronto Press, 2003, p. I65-I92.(págs. I67 y I86-7) señala la indiferenciación con que se tratan los «grandes riesgos» y los pequeños o los «riesgos de vida cotidiana», cuando en los concretos regímenes de prácticas, el tratamiento de unos y otros es de hecho bien distinto y combina enfoques innovadores con una mayoría de tratamientos tradicionales, que han adoptado el lenguaje de los riesgos como el nuevo título de legitimidad de su intervención.

I9 Dean, M., Governmentality: power and rule in modern society, cit. pág. I82.

${ }^{20}$ LEMKE, T. «Los riesgos de la seguridad: liberalismo, biopolítica y miedo», Michel Foucault: neoliberalismo y biopolítica, en V. Lemm (ed.), (D. Rosello, trad.), Santiago, Chile, Universidad Diego Portales, 20Io, p. 247-274 (págs. 258-9).
} 
Esta intensa incorporación de nuevos objetos y asuntos a las actividades de gobierno ha sido el marco de emergencia de una biopolítica, donde la acción y la reflexión de gobierno (a no identificar de forma plena con la acción y reflexión del Estado) tiende a abarcar, no solo las necesidades más básicas e inmediatas, sino un conjunto cada vez más extenso y más profundo de manifestaciones de la vida humana. Durante el siglo XIX, éste constituye el contexto de re-configuración del problema de la seguridad, que antes se ligaba al mercado de manera más exclusiva. Nuevo marco de la seguridad material, que ya no puede disociarse por completo ni del problema de la seguridad ante el delito ni del problema de la seguridad interna del mercado.

Para elaborar un marco útil al análisis de las políticas criminales y sociales contemporáneas, conviene antes analizar la formación de esta actividad de gobierno de la incertidumbre durante la modernidad. En una genealogía sucinta de estas cuestiones, tomaremos algunos procesos que reflejan bien cómo se especificaron distintas manifestaciones de la cuestión de la incertidumbre a partir de las primeras racionalidades gubernativas, a fin de alcanzar una nociones de riesgo más eficaces dentro de nuestro enfoque y de poder contrastar esto con las políticas actuales. En este sentido, el primer campo de desarrollo moderno de los dispositivos de gobierno de la incertidumbre ha sido la regulación de la responsabilidad civil.

La cuestión surgió ligada a los sucesos accidentales, a los imprevistos y a la regulación de la asunción de los riesgos y las responsabilidades en estos casos ${ }^{21}$. Los sucesos que aparecieron, fruto del proceso de industrialización de la economía, durante la última mitad del XIX, guardaban diferencias importantes respecto a las eventualidades que podían producirse durante la era comercial y mercantilista. Estos accidentes industriales podían afectar a terceros, sea a asalariados o a clientes, que no tenían una participación económica en aquello que ocurría. En último término, suponían una constante distorsión de las relaciones productivas, ya que el asalariado apenas tenía medios para probar la responsabilidad del empresario y cuando lo hacía, las indemnizaciones podían afectar a la estabilidad de la empresa ${ }^{22}$. En general, estos accidentes casi siempre podían relacionarse con una cierta responsabilidad, con una falta de diligencia o de atención, pero muchas veces la entidad de esa falta era mínima en la complejidad creciente de los procesos productivos. $\mathrm{Y}$, además, era frecuente que los implicados no tuvieran capacidad económica suficiente para atender a aquella responsabilidad.

En paralelo, la razón de Estado se centraba precisamente en la maximización de sus fuerzas interiores, con voluntad de eliminar o reducir las interacciones que las perjudicaban. Para ambos conjuntos de intereses, el centro del problema se refería a una suerte de responsabilidad sin culpa u objetiva, como desarrolló la dogmática civil ${ }^{23}$. El

\footnotetext{
${ }^{21}$ EWALD, F. L'Etat providence, I ${ }^{a}$ edición, Paris, Bernard Grasset, I986a (págs. 47-85).

${ }^{22}$ DONZELOT, J. La Invención de lo social: ensayo sobre el ocaso de las pasiones políticas (H. Cardoso, trad.), I ${ }^{\mathrm{a}}$ edición en castellano, Buenos Aires, Nueva Visión, 2007 (pág. 95).

${ }^{23}$ Aunque las comparaciones en este terreno requerirían mayores posibilidades de contextualización, la regulación española de la responsabilidad civil ha vivido un proceso análogo. El derecho romano no reconocía un concepto genérico de culpa, sino que la diligencia exigible venía determinada por cada tipo de contrato (LACRUZ BERDEJO, J. L. y RIVERO HERNÁNDEZ, F.Elementos de Derecho Civil, 4 a edición, Madrid, Dykinson, 2007, págs. I64-9). En la regulación resultante de la codificación española, tanto la modalidad de responsabilidad contractual como la extracontractual tienen su fundamento en un principio general de neninemlaedere en una idea de responsabilidad por la que, si alguien causa un daño, debe resarcirlo. En el caso francés, la solución del código napoleónico fue establecer el estándar de la diligencia propia de un buen padre de familia. Con este estándar como punto de partida, el derecho privado ha tendido a ajustar la responsabilidad a la naturaleza y circunstancias del contrato (arts. I. Ior y ss Código Civil). Dentro de esta tendencia se ha llegado a especificar un tipo de responsabilidad exigible incluso en los casos en que no existe una culpabilidad directa en el evento dañoso. Respecto a la responsabilidad extracontractual, la evolución ha sido similar. En los sistemas jurídicos primitivos la responsabilidad penal y la civil permanecían confundidas. Incluso en sus «Instituciones», Justiniano denomina los ilícitos civiles como «cuasidelitos» [LACRUZ BERDEJO, J. L. y RIVERO HERNÁNDEZ, F. Elementos de Derecho Civil, $3^{\text {a }}$ edición, Madrid, Dykinson, 2005 (págs.. 427-8)]. Ello da cuenta
} 
perjuicio se desliga así de la culpa, de la acción reprochable y, hasta cierto punto, de la indeseabilidad absoluta, dado que se aceptan estos daños en la producción industrial (O'Malley, Risk, uncertainty and government, cit. págs. 35-8). Por tanto, el objetivo es edificar un sistema que minimice los riesgos y repare los daños causados. En caso de que la reparación pase por la indemnización, la tendencia será a considerarla exenta de contenido moral, dotándola de una caracterización que es distinta a la de la sanción.

Podemos señalar algunos hitos en este proceso de configuración de la responsabilidad y de la gestión de la incertidumbre. En primer lugar, Defert ${ }^{24}$ describe el proceso de formación de una responsabilidad patrimonial objetiva en el contexto francés. Durante el siglo XIX se consolidan dos sistemas de responsabilidad diferenciados: uno de enunciación penal, basado en la falta y la culpa, y otro más objetivo, en atención a las reglas del seguro y la práctica mercantil e industrial. En cuanto al segundo sistema, las tecnologías de seguro y estos sistemas de responsabilidad modernos terminan abarcando a toda la sociedad, al margen del comportamiento de los dos sujetos implicados en la relación civil. Por ejemplo, un sistema de seguros unificado, que obtiene una parte de las aportaciones de los empleados y otra parte de la producción, se configura como un coste de producción, susceptible de repercusión final sobre los consumidores; de modo que toda la sociedad, abarcada así por este sistema, constituye la verdadera aseguradora última ${ }^{25}$.

En segundo lugar, Ewald ${ }^{26}$ muestra cómo el riesgo comienza a categorizarse como un capital en el interior de la actividad de los seguros: «No que los seguros sean en sí una combinación, sino algo que, con base sobre la tecnología del riesgo, hace posible un ámbito de combinaciones de seguro configuradas para adaptarse a sus funciones asignadas y a sus efectos-utilidades previstos. Considerado como una tecnología, el seguro es un arte de combinar varios elementos de la realidad económica y social conforme a un conjunto de reglas específicas». Esto implica que no existe una única razón o tecnología del riesgo, sino que ésta solo puede concretarse a través de formas diferenciadas en función del contexto histórico, del imaginario político y de seguros de cada momento, que es lo que permite especificar los usos y necesidades posibles de esas tecnologías. Desde este enfoque, el «seguro puede definirse como una tecnología del riesgo. De hecho, el término riesgo (...) no tiene otro significado preciso que como una categoría de esta tecnología. Riesgo es un neologismo de seguro» ${ }^{27}$.

Esta visión resulta muy interesante porque contrasta con las formulaciones abstractas de riesgo que son más habituales en el enfoque de la sociedad del riesgo. Paradójicamente la opción de conceptuar el par riesgo-seguro como una tecnología abstracta ofrece una noción práctica por completo concreta de riesgo, en cuanto que noción susceptible de y que aun exige contextualización, economización, historización, etc. dentro de un proceso de producción transversal, como el de seguros, y de una pluralidad de

de la visión cercana a la de la responsabilidad penal con la que tradicionalmente se han tratado estos casos de responsabilidad civil. Sin embargo, al tiempo de la codificación francesa, la responsabilidad civil se supeditaba ya tan solo a la culpa levísima y en la regulación del Código Civil español (arts. I902 y ss), la exigencia de culpa o negligencia llega incluso a desaparecer en algunos supuestos (Lacruz, Elementos de Derecho Civil, cit., 2005, pág. 429). En la actualidad, son comunes los sistemas de responsabilidad «objetiva» o «por riesgo» en determinados ámbitos de la actividad, principalmente en los casos en que el sujeto que provoca esa actividad eventualmente lesiva aunque inocente obtiene con ello un beneficio especial. Como mostramos en otro lugar (Vila, El gobierno de la infancia, cit.), el campo penal también está sujeto a estas tendencias.

${ }^{24}$ DEFERT, D. «'Popular life' and insurance technology», The Foucault effect: studies in governmentality, en G. Burchell, C. Gordon y P. Miller (eds.), London, Harvester Weatsheaf, I99I, p. 2II-234 (págs. 2I3-4).

${ }_{25}$ O’Malley, Risk, uncertainty and government, cit. (págs. 49-52) introduce el ejemplo más contemporáneo del «derecho del consumo» en esta línea de extensión de los regímenes de responsabilidad y distribución de riesgos ligados al desarrollo de las relaciones de producción.

${ }^{26}$ Ewald, Insurance and risk, cit. pág. I97.

${ }^{27}$ Ewald, Insurance and risk, cit. pág. I98. 
procesos productivos y vitales que se aseguran. Remarca Ewald: «en el lenguaje cotidiano, el término 'riesgo' se entiende como sinónimo de peligro, para algún evento desgraciado que puede ocurrirle a alguien ( $\cdots)$. En seguros, el término no designa ni a un evento ni a un tipo general de acontecimiento (los desafortunados) que ocurren en realidad, sino a un modo específico de tratar ciertos eventos susceptibles de ocurrir a un grupo de individuos ${ }^{28}$.

También ésta aparece como una buena línea de contraste con los enfoques más conocidos de la sociedad del riesgo. Mientras que, allí, el riesgo parece la frontera del saber y de las posibilidades de gobierno, aquí, es su inicio. Desde una perspectiva foucaultiana, la relación de la actividad de gobierno con la de riesgos no es la de una actividad exterior, reactiva o incluso preventiva, respecto a aquéllos, ni mucho menos la de una disposición pasiva frente a la evolución activa de la modernidad, que sería la fuente de producción de esos riesgos. En este sentido, el riesgo resulta especificado por los aseguradores entre sus clientes empresarios y ello supone la mutación de un conjunto de ideas y percepciones metafísicas, catalizada a través de las técnicas de seguros. La actividad de los aseguradores no es, por tanto, una actividad pasiva respecto a los riesgos, registrándolos y compensándolos, sino activa; es decir, los aseguradores especifican, calculan y definen nuevos riesgos en espacios donde antes no existían. Dotan finalmente de un nuevo tipo de existencia a determinados eventos no ocurridos pero que tienen una probabilidad abstracta de producirse.

Actividades, por tanto, creativas; de forma directa, respecto a estas tecnologías de seguros pero también, de manera indirecta, en relación con los efectos que esta actividad de conocimiento-regulación, de saber-poder, tiene sobre el sentido común de la responsabilidad y sobre la disposición y la organización de todo el plano social, dispuesto como la aseguradora última de los riesgos especificados en estos procesos a través de una racionalización que los integra como costes en las relaciones de producción ${ }^{29} \mathrm{y}$ de consumo ${ }^{30}$.

Esto relativiza la existencia de una gran distancia epistémica y gubernativa entre los riesgos presentes y las posibilidades de previsión y de aseguramiento de esos riesgos, que, para otros enfoques de la sociedad de riesgo, sería una característica diferencial de nuestras sociedades. La visión de Ewald contrasta con esta idea, toda vez que vincula las nociones de riesgos y seguros más con la oportunidad, la probabilidad y el azar, que con una noción de peligro. Es decir, comprende la tensión riesgo-seguro más como una forma de pensar y actuar la realidad que como una entidad en sí. De este modo, la emergencia o el descenso de los riesgos no se debe a un tipo de organización social que los produce como consecuencia de su despliegue, sino a las variaciones en las racionalidades de cálculo que los expresan y que condicionan las posibilidades tanto de aquel desarrollo social como de estos dispositivos de previsión ${ }^{3 \mathrm{I}}$. Por ello, entiende que no se trata tanto de que haya riesgos que no puedan ser calculados por una racionalidad de seguro, esto es, que excedan esa racionalidad de tal modo que no puedan ser inscritos en ella. Sino que son más bien esas racionalidades de seguros las que realizan las especificaciones y cálculos de riesgos en aquellos eventos que antes pasaban desapercibidos o que se tenían por imposibles de racionalizar. Aquellos eventos $u$ objetos que, en sentido gubernativo y a nuestra percepción, no existían. Para nosotros, esto no implica que no exista una dificultad cierta en formalizar o racionalizar ciertos malestares, inconvenientes o sufrimientos del presente. De hecho el desarrollo de una gobernabilidad

\footnotetext{
${ }^{28}$ Ewald, Insurance and risk, cit. pág. I99.

29 Defert, 'Popular life' and insurance technology, cit.

${ }^{3 \circ} \mathrm{O}$ 'Malley, Risk, uncertainty and government, cit. págs. 38-42.

${ }^{3}$ Insistimos en que aquí se está analizando la dimensión gubernativa de ciertos espacios de incertidumbre que se formalizan en el interior de una racionalidad de gobierno en la forma, heterogénea y abierta, de riesgos. Como es evidente, los espacios de incertidumbre que no se abordan desde esta perspectiva, no por ello se aclaran, sino que, más bien al contrario, el hecho de que no lleguen a formalizarse como riesgos, como asuntos de gobierno, equivale a su permanencia en un estado de incertidumbre.
} 
alternativa del presente pasaría por la identificación de las condiciones de producción de estos malestares, por su problematización; pero éste es un terreno político que incluye, aunque desborda, las dificultades técnicas a que alude esa idea de la aparición de nuevos riesgos que no pueden regularse o prevenirse. Desde la perspectiva post-foucaultiana, el telón de fondo de las cuestiones de riesgo no es un déficit de saber o de capacidad técnica, o al menos no solo, sino las distintas orientaciones epistémico-políticas que permiten especificar e intervenir sobre unos riesgos o sobre otros.

Todo ello viene vinculado a una noción de riesgo muy distinta y que está marcada por tres características ${ }^{32}$. En primer lugar, el riesgo es calculable. Esta característica principal lo diferencia de otros fenómenos que resultan absolutamente aleatorios y constituye la condición de posibilidad de su intervención gubernativa. En segundo lugar, el riesgo es colectivo, ya que, aunque los eventos lesivos tengan una fuerte afectación sobre determinados individuos, la noción de riesgo siempre se refiere a una población. En su afectación individual, sería imposible calcular de manera suficiente sus regularidades y probabilidades, de modo que permanecería inaccesible a la intervención.Ésta es una cuestión fundamental para notar el impacto gubernativo de las nociones de riesgo en tanto que se perfila la vía por la que las intervenciones pueden pasar desde la máxima abstracción de los grandes dispositivos de previsión ante contingencias sociales, hasta la máxima individuación de cada expediente personal.

En la misma línea que ejemplifican los seguros, Ewald ${ }^{33}$ nota que la labor de estos agentes es precisamente constituir esa población de referencia, estableciendo las diferentes divisiones y rangos de exposición al riesgo. Así, por una parte, los dispositivos de previsión y aseguramiento funcionan siempre a partir de una socialización de los riesgos. Mientras que, por otra, existe una actividad constante de individuación a partir de la que no todos los sujetos o grupos tienen asignados los mismos niveles de riesgo, sino que estos se determinan en casa caso. Lo interesante es que este nivel de riesgo particular no se deduce de una regla exterior absoluta, sino de una norma inmanente, relativa y dinámica, establecida a partir de su constante puesta en referencia con el conjunto de la población. Ahí puede notarse la diferencia respecto a otras mutualidades o conjuntos de protección (la familia, los sindicatos, las hermandades religiosas, etc.), en cuanto que estas tecnologías de riesgos no implican unas normas de conducta sustantivas, sino que tratan de maximizar la socialización de los riesgos con el mayor grado posible de libertad e indeterminación de la conducta individual; de donde se deduce también su grado de ajuste a la racionalidad liberal de la época ${ }^{34}$.

La tercera característica señala que el riesgo funciona como un capital. Dado que, con frecuencia, el daño sufrido no puede ser compensado ni reparado en sentido estricto, estos dispositivos de aseguramiento ofrecen la garantía de una compensación financiera, que es de otro orden respecto a aquello que resulta indemnizable. Se produce así una dualización del evento, que queda descompuesto entre un daño, irreparable como tal, y una pérdida indemnizable, previa valoración patrimonial. De hecho, ésta es una característica diferencial de las tecnologías de seguro privado, en el contexto de expansión general de sistemas de seguros contrapuestos (compañías aseguradoras, mutualidades obreras y sistemas de previsión estatales) durante el XIX ${ }^{35}$.

\footnotetext{
${ }^{32}$ Ewald, Insurance and risk, cit. págs. 20I-4.

${ }^{33}$ Ewald, Insurance and risk, cit. págs. 203-4.

${ }^{34} \mathrm{O}$ 'Malley, Risk, uncertainty and government, cit. págs. 29-34.

${ }^{35}$ Vid. Defert, 'Popular life' and insurance technology, cit. (pág. 2I2) y, en una clave más subjetiva, RANCIÈRE, J. La noche de los proletarios. archivos del sueño obrero (E. Bernini, trad.), I Ia edición en cast., Buenos Aires, Tinta Limón, 2010 (págs.. I43 Ss). En SUSÍN, R. La regulación de la pobreza: el tratamiento jurídico-político de la pobreza. Los ingresos mínimos de inserción, $\mathrm{I}^{\mathrm{a}}$ edición, Logroño, Universidad de La Rioja, Servicio de Publicaciones, 2000
} 
Amén de ésta, las tecnologías de seguro incorporaron algunas características muy innovadoras y próximas a la gobernabilidad. Por ejemplo, promueven una concepción de la población como una masa homogénea, más a partir de métodos estadísticos que de formas empíricas de solidaridad como la familia, el barrio, etc. Por otra parte, se trata de un método financiero basado, no directamente en la especulación con la muerte y la vida, pero sí con el alargamiento médico de la vida que comienza a producirse. También se trata de la primera racionalización económica de lo que después se denominará capital humano ${ }^{36}$. Asimismo supone una nueva vía de concentración de capital y la especificación de un conjunto de reglas de cuantificación y supervisión de la conducta humana.

Como se observa, éste es otro punto de cruce entre las cuestiones de saber y de formación de un régimen capitalista. De hecho, cierta producción de incertidumbre (o de riesgo en sus declinaciones más controladas) y, por tanto, de apertura social, es uno de los rasgos diferenciales de la gobernabilidad liberal-capitalista, en comparación por ejemplo con otras gobernabilidad formalizadas de manera coetánea, como las socialistas, que apostaban por una reducción de la incertidumbre y la apertura social en beneficio de la planificación centralizada, sobre todo de carácter estatal. Más adelante, veremos que esto se intensifica hasta el extremo en la centralidad que el riesgo tiene para la gobernabilidad neoliberal y, en general, en un capitalismo de tendencia financiera.

Desde luego, esta caracterización no implica la existencia de una única racionalidad de cálculo. Por supuesto, las empresas aseguradoras no son la mano invisible de la regulación de la incertidumbre moderna, así que el objetivo es mejorar la descripción de las tecnologías de riesgo a partir de su funcionamiento concreto en el interior de un régimen de prácticas relevante, que además tiene una conexión visible con otros procesos, como el de estandarización y normación disciplinaria ${ }^{37}$. Presentado así uno de los supuestos típicos de regulación de la incertidumbre dentro del liberalismo, que nos ha permitido ofrecer una visión contextualizada y alternativa del funcionamiento de la noción de riesgo, podemos ver cómo estos procesos de gubermentalización se desarrollaron también en relación con otros espacios de incertidumbre.

\section{II.2. Formación de dispositivos de previsión durante la modernidad}

Para aproximarnos hacia la formación y tratamiento del problema contemporáneo de la seguridad, recorremos la formación de algunos dispositivos de previsión de la incertidumbre durante las primeras etapas del proceso de gubermentalización, centrándonos más en la dimensión gubernativa de estos procesos que, como lo acabamos de hacer, en la concepción diferencial que implican respecto a la noción de riesgo.

Podemos notar un buen ejemplo respecto al propio proceso de formación de los grandes sistemas de seguros, privados y públicos. Ahí vimos cómo, durante el XIX, el riesgo se constituyó en un principio omnímodo y enciclopédico de objetivación de la experiencia posible y no solo de los azares de la vida privada o de la vida social. En esta creación de nuevos planos de gobierno, resultó decisiva la estadística. La irrupción de la probabilidad abre, así, un espacio para las oportunidades de elección que erosiona el determinismo social $^{38}$.

(págs. I66-I78), pueden verse algunas características diferenciales respecto a la formación de estos primeros dispositivos de previsión en el caso español.

${ }^{36} \mathrm{Al}$ principio, el sujeto de ese (proto)capital humano es el propietario de renta, más que el de la fuerza de trabajo.

37 EWALD, F. «Norms, Discipline, and the Law», Representations, 30, I990, I38-16I.

${ }^{38}$ HACKING, I. «How should we do the history of statistics?», The Foucault effect: studies in governmentality, en G. Burchell, C. Gordon \& P. Miller (eds.), London, Harvester Weatsheaf, I99I, p. I8I-I95 (pág. I83). 
Por otra parte, este desplazamiento hacia los mecanismos de previsión social basados sobre la estadística debe situarse en el contexto de la modernidad industrial, donde se han diluido las protecciones familiares y del comunitarismo rural. Éste es el contexto de surgimiento de los dispositivos de aseguramiento, sea en forma de mutualidades obreras o de empresas aseguradoras. En cualquier caso, todas ellas requieren trabar conocimiento de las regularidades de producción de los eventos dañosos para poder asegurar frente a ellos, lo que supone una fuerte demanda de conocimiento estadístico ${ }^{39}$. Así, la evolución de estos saberes es pragmática, como un inicio de solución ante estos problemas de seguridad acuciantes y sin una reflexión sobre su metodología comparable con la inmensa cantidad de datos que comienzan a registrarse. En estos momentos, se trata, más bien, de un saber del contar.

Desde esta perspectiva, las tecnologías de seguros se consideran como una verdadera tecnología política destinada a conciliar los principios de máxima individualidad y responsabilidad individual con los de máxima solidaridad, distribuyendo socialmente el coste económico de los riesgos ${ }^{40}$. Por eso, más allá de su ámbito objetivo, estas técnicas acaban teniendo un impacto nada menor sobre las reglas de responsabilidad, identidad, agencia, etc., tanto desde una perspectiva social como penal.

Respecto al gobierno de lo social, estas tecnologías permitieron trazar distintas líneas de vinculación entre los planos más colectivos y más individualizados de gobierno, desde la subjetividad legal individual a las formas de asociación y socialización del riesgo. En este sentido, los seguros son siempre colectivos (definidos en función de la colectividad y empleados para restaurar de algún modo el orden armónico), aunque se calculen y se acceda a ellos individualmente. Así, se entiende la genealogía de los seguros sociales para los trabajadores y su carácter de tecnología política, como instrumento de gobierno social ${ }^{4 \mathrm{I}}$.

Estas tecnologías de seguro, como dispositivos de gobierno de la incertidumbre, ofrecen nuevas visiones sobre la cuestión de la seguridad liberal. En la producción controlada de libertad que caracteriza las estrategias liberales de seguridad, se calcula el efecto que tiene sobre la seguridad de los otros y la seguridad general determinadas producciones de libertad: en esta maximización de los intereses en competencia, gobernar sería calcular y limitar aquellos que pueden afectar negativamente la seguridad de los otros. Esto es, producir libertad y administrarla de modo que los distintos intereses estén lo menos expuestos posible a los riesgos ${ }^{42}$. Por tanto, la administración de los riesgos es una tarea principal del gobierno liberal: «la divisa del liberalismo es 'vivir peligrosamente'. 'Vivir peligrosamente', esto es, que los individuos se vean a perpetuidad en una situación de peligro o, mejor, estén condicionados a experimentar su situación, su vida, su presente, su futuro, como portadores de peligros» ${ }^{43}$. Ello inicia, en el siglo XIX, una cultura del peligro cotidiano, que tiene su correlato en una cultura de la seguridad cotidiana ${ }^{44}$. Éste es el marco

\footnotetext{
${ }^{39}$ Hacking, How should we do the history of statistics?, cit. pág. I9I.

${ }^{4}$ Ewald, Insurance and risk, cit. págs. 20I-4.

${ }^{4 \mathrm{I}}$ Vid Defert, 'Popular life' and insurance technology, cit. (págs. 222 ss) respecto a la vinculación entre el surgimiento, dentro de estas tecnologías, de las mutualidades obreras, la formalización de los seguros sociales y la formación de las nociones durkheimianas de sociedad y solidaridad durante la III República Francesa.

${ }^{42}$ Foucault, Nacimiento de la biopolítica, cit. págs. 85 ss.

${ }^{43}$ Foucault, Nacimiento de la biopolítica, cit. pág. 87.

${ }_{44}$ Desde una perspectiva cultural, la exigencia jurisprudencial de un principio de buena fe y confianza generalizada (ubérrima fides) entre las partes del seguro podría leerse en esta dirección de conformar un campo de relaciones sociales afines a los requerimientos del mercado, unas «economías de la confianza», en las que fueran también centrales el auto-conocimiento y la expresión de las propias circunstancias de vida. Tal como indica LOBO-GUERRERO, L. «Uberrima fides, foucault and the security of uncertainty», International Journal for the Semiotics of Law, published online I8 april, $20 \mathrm{I} 2$ (pág. I3): «El principio de ubérrima fidesse convierte a este respecto, no en una 'región prefabricada que necesite ser respetada', sino en 'una propuesta de producción' de confianza a través de unas relaciones en las que la contraparte fuerza la revelación de las circunstancias materiales mediante un complejo conjunto de tecnologías morales». La relevancia de la confianza y en general de las relaciones sociales de fondo no ha dejado de aumentar en el capitalismo financiero contemporáneo.
} 
de proliferación de las campañas e instituciones de ahorro y previsión voluntarias, como las cajas de ahorro ${ }^{45}$, de la higiene y la protección frente a la mala sexualidad y su potencia degenerativa o de la literatura policíaca: «temor al peligro que en cierto modo es la condición, el correlato psicológico y cultural interno del liberalismo» ${ }^{46}$.

Pero también es la época en que están en auge las instituciones de previsión obreras, como las sociedades de socorro y las mutualidades, que si bien contaban con una eficacia y capacidad de impacto sistémico limitada, dada su composición restringida y su evolución de clase $^{47}$, muestran la relevancia política de las tecnologías de seguro en la época. El empuje que esto tuvo sobre las tecnologías de previsión estatales constituye uno de los ejemplos más claros de problematización de la incertidumbre dentro de un proceso de gubermentalización ${ }^{48}$, en cuanto pretenden la movilización de las clases populares hacia la adopción de tácticas y concepciones de la vida basadas sobre la ética de la individualidad y los riesgos profesionales. Asimismo, significa bien la posición del Estado y de determinados «nodos de poder», que no es exclusiva pero sí muy relevantes en esta actividad de gobierno $^{49}$. En definitiva, los seguros sociales son un ejemplo privilegiado del carácter central que el concepto de seguridad y de políticas de seguridad adquierenen la actividad de gobierno, amén de reflejar la riqueza y la complejidad de estos procesos de gubermentalización.

La implicación de las poblaciones destinatarias de la seguridad, respecto a la formación de la razón de Estado desde el siglo XVII, muestra cómo la noción moderna de seguridad ha desplazado sus objetivos desde la mera conservación del Estado, hacia el mantenimiento de aquella regularidad o situación de equilibrio que permite maximizar los efectos positivos de las circulaciones biopolíticas y minimizar los negativos, estableciendo sistemas de control con capacidad de adaptación a las particularidades del entorno ${ }^{50}$.Algunos discursos actuales de la sociedad del riesgo inciden en esta problematización de la seguridad, que «se ha convertido en la carta legitimadora por excelencia del Estado moderno» ${ }^{5 \mathrm{I}}$. Por supuesto, los nuevos abordajes, a partir de dispositivos de seguridad, no han sustituido totalmente las técnicas anteriores ni resultan por completo nuevos respecto a aquéllas, por lo que debe pensarse en una nueva correlación de fuerzas entre los distintos diagramas de poder y analizar en cada caso la impronta de sus características distintivas.

Sin embargo, ya notamos al inicio las dificultades de ambigüedad y confusión que encontrábamos al querer analizar este campo del gobierno de la incertidumbre, debido a la polisemia y al escaso rigor con que en ocasiones se trata el complejo de riesgo-seguridadincertidumbre ${ }^{52}$. A este respecto y siguiendo la línea foucaultiana de problematización, conviene precisar la noción de seguridad a partir de su distinción respecto a otras nociones contemporáneas próximas. En la práctica, esto es sobre todo si la noción se limita a la

\footnotetext{
${ }^{45}$ CASTEL, R. La metamorfosis de la cuestión social: una crónica del salariado (J. Piatigorsky, trad.), I ${ }^{a}$ edición, Buenos Aires, etc., Paidós, I997, págs. 250-2.

${ }^{46}$ Foucault, Nacimiento de la biopolítica, cit. pág. 87.

${ }^{47}$ Donzelot, La invención de lo social, cit., pág. 99; Castel, La metamorfosis de lo social, cit., págs. 292-3.

${ }^{48} \mathrm{O}$ 'Malley, Risk, uncertainty and government, cit. págs. 42-6.

${ }^{49}$ ROSE, N. \&MILLER, P. «Governing economic life», Economy and Society,I9(I), I990, p. I-3I (pag. I5).

${ }^{50} \mathrm{Hood}$, El gobierno del riesgo, cit. pág. 4I.

${ }^{51}$ Prieto, Sobre los límites y posibilidades de respuesta jurídica al riesgo, cit., pág. 37.

${ }^{52}$ JONES, T. (2007) «The governance of security: pluralization, privatization, and polarization in crime control», The Oxford Handbook of Criminology, en M. Maguire, R. Morgan \& R. Reiner (eds.), 4 a edición, Oxford, Oxford University Press, 2007, p. 84I-865 (pág. 844).
} 
evitación del delito, en su dimensión más común hoy y vinculada a las fuerzas de policía ${ }^{53}$, o si se trata de una noción más amplia. En el contexto español, éste parece el criterio de distinción entre las nociones de seguridad pública y la más limitada de seguridad ciudadana ${ }^{54}$. La seguridad pública, caracterizada como la «competencia de las instancias públicas cuyo objetivo consiste en establecer, mantener y eventualmente restaurar las condiciones de un estado de convivencia que permita el efectivo ejercicio de derechos y libertades» (Recasens, 2007: 133) se situaría en un plano convivencial y sistémico de envergadura, coincidente con el plano de equilibrio de la sociedad y ligado no solo al disfrute individual de derechos, sino a la organización propia de un Estado social y democrático de derecho. En la medida en que ésta se convierte en una noción de seguridad cada vez más prevalente para las visiones complejas de la organización social (Pitch2009, 3I-3 para las actuales criminologías postcríticas), incluso en una dimensión internacional (Hammer2007), se advierte con claridad cómo su gobierno no puede satisfacerse en exclusiva a través de la actividad, en su mayoría negativa, de las fuerzas y cuerpos de seguridad, sino que exige la articulación de dispositivos de seguridad más amplios en sus objetos, ámbitos de intervención y funciones, que incorporen así toda la positividad de gobierno.

De manera reciente, otros enfoques han avanzado en las investigaciones sobre seguridad a partir de esta dinámica foucaultiana de desnaturalización y problematización de tales cuestiones. Al principio respecto al ámbito de las relaciones internacionales, el colectivo C.A.S.E. ${ }^{55}$ introdujo la noción de securización, con objeto de subrayar la performatividad de ciertos discursos y actos en la configuración de estos asuntos y la contingencia de sus formaciones teóricas y técnicas. Desde una posición más interesada en la soberanía que la foucaultiana, este enfoque ponía como ejemplo de tales técnicas y actos de securización los discursos que ligaban determinados asuntos de la realidad social a condiciones existenciales, como el bienestar de las poblaciones, los principios y valores constitucionales, etc ${ }^{56}$.

De hecho, los problemas contemporáneos de seguridad, tal y como los analizamos, tienen mucha relación con la re-configuración epistémica y el estrechamiento político de estas nociones. La crisis del welfare y la consiguiente retracción de sus objetivos de previsión social reducen asimismo el ámbito de estas políticas ${ }^{57}$ y modifican el sentido de la participación de los agentes estatales ${ }^{58}$. En esta línea, Bauman ${ }^{59}$ destacó también tal retracción, desde un concepto de seguridad más general (security) hacia un concepto de seguridad más ligado a la protección personal-individual y derivada de aquella (safety), dentro de un proceso más amplio hacia la individualización de la sociedad a lo largo de la modernidad tardía y a la evolución del Estado del bienestar hacia un paradigma individualizante de «sálvese quien pueda». En cualquier caso y sin desconsiderar ni las dificultades de coyuntura, ni las disfuncionalidades

${ }^{53}$ BRANDARIZ GARCÍA, J. Á. «Nuevos riesgos, nuevas ansiedades y expectativas sociales en materia de seguridad ante el delito», Derecho penal de excepción: Terrorismo e inmigración, en Faraldo Cabana, Patricia et al. (eds.), Valencia, Tirant lo Blanch, 2007, p. I39-I60, se refiere a esta como una reducción del concepto de seguridad a su metonimia en el ámbito del derecho y el control penal.

${ }^{54} \mathrm{Vid}$. Recasens, La seguridad y sus políticas, cit. págs. I32-9.Encontramos ahí también una distinción jurídica de las nociones de «seguridad pública» y «orden público» para el ámbito histórico y político español (Recasens, $L a$ seguridad $y$ sus políticas, cit. págs. 36-9).

55 C.A.S.E. Collective, «Critical approaches to security in Europe», 20II (disponible en http://www.casecollective.org/; fecha de consulta: I0.4.20II).

${ }^{56}$ OPITZ, S. «Government unlimited: the security dispositif of illiberal government», Governmentality: current issues and future challenges, en U. Bröckling, S. Krasmann \& T. Lemke (eds.), New York, etc., Routledge, 20II, p. 93-II4 (págs. IOI Ss).

${ }^{57}$ Recasens, La seguridad y sus políticas, cit. págs. I58-159.

${ }^{58} \mathrm{PITCH}, \mathrm{T}$. «¿Son posibles las políticas democráticas para la seguridad?», Revista Catalana De Seguretat Pública, 20, 2009: 29-49 (págs. 38-45).

59 Bauman,Tiempos líquidos: vivir en una época de incertidumbre, cit. págs. 24-6. 
de orientación, coordinación y operatividad ${ }^{60}$, lo relevante es mostrar cómo el mantenimiento de la seguridad en el presente está marcado por este desajuste entre la amplitud de los problemas de seguridad que pueden especificar unos saberes de gobierno contemporáneos y el estrechamiento de los métodos de mantenimiento de la seguridad y control social que pueden implementarse en un contexto político post-welfarista ${ }^{6 \mathrm{I}}$.

En principio, este recorrido desde los discursos más extendidos sobre riesgo hasta una conceptuación más coherente con nuestro marco de la seguridad, será útil en varios sentidos. En primer lugar, permitirá, por contraste, situar los discursos sobre el riesgo, en expansión para distintos ámbitos, dentro de unas racionalidades políticas y estrategias de gobierno más amplias y con mayor capacidad explicativa del presente. En segundo lugar, nos permitirá declinar con mayor precisión estas políticas de seguridad en un plano penal y en un plano social, así como en análisis relativos a categorías sociales específicas ${ }^{62}$.

\section{Algunas tendencias contemporáneas en el gobierno de la incertidumbre a través del riesgo}

Quizá la vía más evidente de problematización de la seguridad haya sido la referida a la defensa social, en términos negativos, y al fomento de las fuerzas del Estado, en términos positivos, sobre todo durante el siglo XIX. Desde esta combinación, la seguridad se protegería a través de la emergencia y delimitación de la peligrosidad y de las clases peligrosas, no solo como una forma de dar cobertura discursiva al tratamiento de estas poblaciones, sino como un medio de constante definición de qué podía entenderse por seguridad en las incipientes sociedades industriales y que otros asuntos no podían encuadrarse en esta preocupación principal del gobierno, sino que quedaban más bien como circunstancias de la vida personal de ciertos individuos y grupos de población. Sin embargo, no recorreremos aquí con más detalle estos procesos, sino que nos centraremos en la evolución de las políticas de seguridad en el sentido más amplio que expusimos.

Desde una perspectiva foucaultiana, que liga la emergencia de estas nociones y tecnologías de riesgos a las dinámicas de saber-poder y a los procesos de gubermentalización de las relaciones, la literaturaha seguido tres líneas de evolución ${ }^{63}$. Una, centrada en el análisis del desarrollo de estas perspectivas de riesgo en ámbitos de la vida social donde antes eran desconocidos, como la salud o las políticas activas de empleo. Otra línea, en la estela de los trabajos de Ewald y Defert que hemos revisado arriba, realiza la genealogía de distintos aspectos o técnicas de riesgo, a fin de concretarlas y medir mejor sus impactos y alternativas a través de una problematización del presente. Por último, hay una tendencia, que es la que mejor atiende al contenido de este artículo, donde se trata de inscribir el análisis de estas tecnologías dentro de uno más amplio y alusivo a las racionalidades de gobierno, como el neoliberalismo, el welfarismo, el neo-conservadurismo, etc., en cuyo interior no deja de realizarse un trabajo de especificación de nuevos riesgos y de articulación de políticas de seguridad.

\footnotetext{
${ }^{60}$ Recasens, La seguridad y sus políticas, cit. págs. I64-I68.

${ }^{6}$ Vid.ESPOSITO, R. Comunidad, inmunidad y biopolítica (A. García Ruiz, trad.), I Ia edición en castellano, Barcelona, Herder, 2009, respecto a la contradicción latente en las dinámicas de inmunización. En un sentido similar, Opitz, Government unlimited: the security dispositif of illiberal government, cit. págs.97-9, se refiere a este desajuste como la «aporía» de la seguridad en los actuales dispositivos y técnicas de intervención.

${ }^{62}$ Vila, El gobierno de la infancia, cit.

${ }^{6} \mathrm{O}^{\prime}$ Malley, Risk, uncertainty and government, cit. págs. 7-I2.
} 
A este respecto, $\mathrm{O}^{\prime}$ Malley ${ }^{6}$ ha identificado una tendencia de nuevoprudencialismo. Respecto al prudencialismo industrial del siglo XIX, la responsabilidad sobre la producción de riesgos se extiende a nuevos niveles, se generaliza desde el cuerpo de ciudadanos activos hasta las clases pobres o desproletarizadas y otro tanto ocurre respecto a las actividades productoras de riesgo ${ }^{65}$. Anteriormente, la gobernabilidad keynesiana, en la que incluimos los modelos de liberalismo welfarista propios de buena parte del siglo XX, conservó, con el riesgo, esa relación de funcionalidad propia del liberalismo pero trató también de minimizar y de controlar algunos de esos espacios de incertidumbre social. Frente a la racionalidad del mercado y sus riesgos sobre la seguridad general del sistema, el Estado (y los saberes expertos que asoció) se constituyó en el agente principal de gestión de riesgos, en tanto que el único capaz de intervenir en el plano sistémico de su producción ${ }^{66}$. Por otra parte, esta dimensión estructural de los riesgos absorbe buena parte de la responsabilidad de los individuos y grupos sociales: los sistemas keynesianos-welfaristas de previsión de la incertidumbre, consideran a los individuos y grupos sometidos a mayores riesgos como los menos capaces de incidir autónomamente en su gestión. De ahí que sean, a su vez, los mayores beneficiarios de los sistemas de previsión y también los grupos sometidos a mayor intervención.

Sin embargo, en el neoliberalismo, esta relación con el riesgose invierte y se refuerza su ligadura respecto a la producción y a la seguridad ${ }^{67}$ : no hay innovación, beneficio o éxito, ni para las empresas ni para los individuos mismos, sin asumir riesgos. Y, sin todo ello, no es posible mantener la seguridad en cuanto continuidad de las normas de convivencia existentes ${ }^{68}$. Como es evidente, esta concepción modifica los efectos y el sentido político de las tecnologías basadas sobre el riesgo respecto al keynesianismo: si el riesgo se constituye a partir del comportamiento interesado de los agentes económicos y de los individuos, serán éstos, sujetos racionales y responsables, los que deban gestionar sus propios riesgos.

Podemos describir las innovaciones de esta situación desde un doble movimiento. En primer lugar, se aprecia una intensificación de la tendencia a interiorizar el peligro en la propia dinámica social. Como vimos, se trata de un proceso de gubermentalización que deja de considerar los peligros como «exteriores» para referirlos al exceso mismo del funcionamiento social (infección, contaminación, perversiones, indisciplina, etc.) o a la ausencia de control y de autolimitación en las relaciones sociales (descontrol, virus). De este desplazamiento en la problematización se derivan otras soluciones: bien las formas de policía, reglamentación y aparatos disciplinarios, bien los mecanismos de (auto)regulación, incorporados a los propios procesos sociales (límites de tolerancia, índices de riesgo, factores, dispositivos de seguridad, etc.).

En segundo lugar, se aprecia un desplazamiento en las mismas nociones de riesgo, incertidumbre, seguridad, responsabilidad, etc. en el neoliberalismo. Es oportuno recordar aquí la distinción que propone $\mathrm{O}^{\prime} \mathrm{Malley}^{69}$ entre incertidumbre y riesgo. De una parte, la incertidumbre, como indeterminación de los posibles en el futuro, es, para el neoliberalismo, incluso más relevante que para el liberalismo, toda vez que constituye la clave de su

\footnotetext{
${ }^{64}$ O'MALLEY, P. (I992) Risk, power and crime prevention.Economy and Society, 2I(3), I992, 36I-374.ídem; «Risk and responsibility», Foucault and political reason. Liberalism, neo-liberalism and rationalities of government, en A. Barry, T. Osborne y N. Rose (eds.), London, UCL Press, I996, p. 189-207.

${ }_{5}^{6}$ M. Dean, Governmentality: power and rule in modern society, cit. pág. I66.

${ }^{66}$ Puede ampliarse este enfoque en las intervenciones de Pat O’Malley en el seminario dirigido por Mariana Valverde: VALVERDE, M. Radically rethinking regulation. Workshop report. Material no publicado. Instituto Internacional de Sociología Jurídica de Oñati (Guipúzcoa), I994 (fecha de consulta: I4.Io.20Io).

${ }^{67}$ Foucault, Nacimiento de la biopolítica, cit.

${ }^{68}$ Recasens, La seguridad y sus políticas, cit. págs. I32 Ss.

${ }^{69}$ O’Malley, Risk, uncertainty and government, cit. pág. 76.
} 
organización productiva ${ }^{70}$. De otra parte, el riesgo permanece como modalidad de incertidumbre más determinada, controlada o, al menos, formalizada y especificada en el contexto de determinados dispositivos de cálculo y aseguramiento. La cuestión es que, en el neoliberalismo, se intensifican estas dinámicas de fomento de la incertidumbre o de desterritorialización, mientras que el espacio de la noción de riesgo se reduce, toda vez que esos dispositivos que permiten su socialización se limitan también y la incertidumbre pasa a individualizarse ${ }^{7 \mathrm{y}} \mathrm{y}$ a aumentar la responsabilidad de cada cual por su control.

Desde esta particular escisión entre riesgo e incertidumbre, la cuestión clave es la determinación de las incertidumbres que se considerarían relevantes para la seguridad y que por tanto serían estudiadas, formalizadas dentro de esquemas de riesgos y finalmente sometidas a programas de previsión y prevención de sus efectos dañosos. Ésta es la clave de la política contemporánea, cuyas transformaciones se referirían a la evolución de los espacios de incertidumbres delimitados y sometidos a intervención y en el contenido de tales políticas de previsión.

Ewald ${ }^{72}$ dibuja una última línea de desplazamiento al introducir la noción de precaución, que dibuja un diagrama de gobierno de la incertidumbre y del riesgo algo distinto al que se había consolidado durante el welfarismo. El diagrama de precaución contrastaría con el de responsabilidad y providencia del siglo XIX y el de prevención y solidarismo del XX. El principio de precaución se basa sobre la constatación de que determinados comportamientos no solo ponen en riesgo al actor, sino también a la colectividad $^{73}$, pero de un modo distinto al que fundaba los dispositivos de prevención colectiva del welfarismo. En principio esto se debe a las condiciones especiales de los eventos a los que se aplica este principio de precaución, formulado en el interior del derecho medioambiental. Aunque la literatura reconoce con mayor frecuencia este régimen respecto a las catástrofes ${ }^{74}$, que en el tratamiento de los riesgos cotidianos, la hipótesis de Ewald es que esta novedad supone cambios en la configuración y la gestión de riesgos que no se detienen en sus ámbitos de aplicación estricta, sino que comportan un efecto sistémico, al igual que los regímenes de responsabilidad anteriores. De hecho, este nuevo prudencialismo puede ocupar desde perspectivas más penales espacios regulativos y de definición de riesgos antes liderados por racionalidades más welfaristas y sociales ${ }^{75}$.

En todo caso, cuando se habla de una menor protección ante los riesgos en el interior del neoliberalismo, hay que precisar esta evolución. Por un lado y desde la situación del welfare, el Estado ya no es el oasis de racionalidad en medio de la disfuncionalidad del mercado ${ }^{76}$. Este cambio no afecta a todas las incertidumbres por igual porque el Estado se

${ }^{70}$ BOLTANSKI, L. y CHIAPELLO, E. El nuevo espíritu del capitalismo (M. Pérez Colina, A. Riesco Sanz y R. Sánchez Cedillo, trads.) I Ia edición, Madrid, Akal, 2002.

${ }^{71}$ Rose, Governing economic life, cit., págs. 23-24.

${ }^{72}$ EWALD, F. «The return of Descartes's malicious demon: an outline of a philosophy of precaution» Embracing risk: the changing culture of insurance and responsibility, en T. Baker y J. Simon (eds.) (S. Utz, trans.), Chicago, London, The University of Chicago, 2002, p. 273-30I (págs. 273-4).

${ }^{73}$ Ewald, The return of Descartes's malicious demon, cit., pág. 274.

${ }^{74}$ HAGGERTY, K. D. «From risk to precaution: the rationalities of personal crime prevention», Risk and morality, en R. V. Ericson \& A. Doyle (eds.), Toronto, University of Toronto Press, 2003, p. I93-2I4 (págs. I98203).

${ }^{75}$ ROSE, N. «Government and control», The British Journal of Criminology,4O(2), 2000, 32I-339 (págs. 3278) y DEAN, H. Social policy. I ${ }^{\mathrm{a}}$ edición, Cambridge, etc., Polity Press, 2006 (pág. I03).

$7^{6}$ Para DONZELOT, J. «The mobilization of society», The Foucault Effect: studies in governmentality, en G. Burchell, C. Gordon y P. Miller (eds.), London, Harvester Weatsheaf, I99I, p. I69-179 (pág. I75), el cambio en la organización del welfare se explica a partir de los cambios en las funciones de estos dispositivos de previsión durante la modernidad tardía. En primer lugar y respecto a la relación moderna entre solidaridad y soberanía como criterios rectores de la posición del Estado respecto a la sociedad en el welfare. Desde esta perspectiva, el Estado tiene ahora mayores dificultades para articular los dispositivos de solidaridad orgánica necesarios para su 
había convertido en el principal espacio institucional para la captación de recursos y la previsión de ciertas incertidumbres que afectaban a las clases medias y bajas. Por otro lado, otros saberes expertos de previsión han proliferado en el interior del mercado al calor de su competitividad, desde el ímpetu del marketing a los sistemas de seguridad privada, pasando por los entrenadores personales. En este ámbito privado, se han desarrollado sistemas expertos autónomos para una previsión y gestión de los riesgos tan capaces como los dispositivos estatales pero que no los han sustituido en cuanto a su extensión sobre todas las poblaciones. Por tanto, se ha producido un declive respecto al papel de los sistemas expertos integrados en la gobernabilidad estatal durante el welfare, a la vez que estos $u$ otros expertos conservan una considerable capacidad de «promoción» o de visibilización de riesgos en determinados contextos ${ }^{77}$.

Por supuesto, no solo se han dado giros en los agentes de previsión de los riesgos, sino también en el ethos de estos regímenes de regulación. A este respecto, es consistente la literatura que ha destacado el proceso de mayor responsabilización de los sujetos pasivos de los riesgos. Técnicamente esto se ha realizado y ha venido animado al centrar la valoración de riesgos y la intervención en los comportamientos de aquellos grupos más afectados, lo que tiende a orientar las políticas hacia la modificación directa de los comportamientos de esos grupos, identificados como factores muy influyentes en tales riesgos. El gobierno de los riesgos se aproxima así a la racionalidad del mercado; esto es, a una distribución competitiva de los riesgos que premia los aciertos y castiga los fallos, favoreciendo así un incremento en la eficiencia de los comportamientos. Esta visión justificará la mayor competencia de los sistemas de previsión social privados en ámbitos como la salud, la seguridad o las contingencias tanto de la edad como de los tipos de interés. Tal como ocurría con los primeros sistemas de previsión liberales ligados a la proletarización y a la familiarización (con todas sus conexiones), estos regímenes tienen un notable efecto en la sujeción de estos grupos ${ }^{78}$.

En sus expresiones más directas, esta sujeción sería escasamente liberal. La lectura más particular en este sentido sería la de Alan Hunt ${ }^{79} q u e$ no considera este desplazamiento en la clave neoliberal de la mercantilización, sino en la clave neo-conservadora de la moralización. Si nos referimos a los riesgos cotidianos, conviene notar que éstos no estánregulados por regímenes de prácticas técnicos y expertos, tanto como por normas, jurídicas y morales, menos sofisticadas y con mayor capacidad de sujeción y de autoresponsabilización: del «prohibida la entrada» al «por su seguridad, no entrar» ${ }^{80}$.

De todos modos y cualquier que sea la matriz política en que se encuadren estas transformaciones, la generalización de una capacidad de auto-gobierno se ha reforzado como componente fundamental del mantenimiento de la seguridad. Al respecto de las políticas de previsión, esto dibuja una transición muy clara desde la regulación por solidaridad, según la notable fórmula de los dispositivos de previsión welfaristas, como los seguros sociales, por los que se combina la maximización del interés individual con la maximización de la socialización del interés; hacia una auto-regulación y auto-previsión ${ }^{81}$, donde siempre existe un objetivo último de conducción de los otros o de promoción de ciertas conductas, como el

\footnotetext{
intervención sobre la sociedad y por otra parte, este Estado ocupa una proporción creciente de la soberanía efectiva que se había reservado a la sociedad.

77 Hunt, Risk and moralization in everyday life, cit., págs. I69-I70.

$7^{8}$ Garland, The rise of risk, cit., págs. 65-68.

${ }^{79}$ Hunt, Risk and moralization in everyday life, cit., pág. 165.

${ }^{8 \circ}$ Hunt, Risk and moralization in everyday life, cit., págs. I76-I78.

${ }^{8 \mathrm{I}}$ ROSE, N. Powers of freedom: reframing political thought, $7^{\mathrm{a}}$ reimpresión, Cambridge, Cambridge University Press, 2007, pág. 158.
} 
auto-aseguramiento, la búsqueda activa de ingresos complementarios o de la seguridad en el trabajo ${ }^{82}$.

Dentro de un proceso de dispersión o de pluralización de los factores de riesgopeligrosidad y a diferencia de lo que entienden las perspectivas de la «sociedad del riesgo», cada vez se consideran mayores las capacidades de los individuos para gestionar por sí estos riesgos. Esta complejidadimpide una división dicotómica entre los individuos, los grupos y las actividades que no comportan riesgo y las que son peligrosas y obliga, más bien, al establecimiento de un tejido de management del riesgo a lo largo de toda la población. Sin embargo, tal ubicuidad no disuelve por completo ciertas «líneas duras» de las categorías sociales de la gobernabilidad welfarista-disciplinaria, cuyo extremo serían las clases peligrosas, sino que más bien tiene un efecto de nueva distribución de las categorías y divisiones sociales.

Dada esta fluidez en los nuevos discursos del riesgo, la división más presente es la que se hace entre los ciudadanos activos (active citizen), capaces de controlar sus propios riesgos, y las poblaciones en riesgo (targetedpopulations), que requieren intervención exterior $^{83}$. La división no es totalmente estanca pero los polos de esta división sí ocupan una posición bastante fija que implica juicios difícilmente revisables sobre el tutelaje o la autonomía de esas poblaciones. El principal efecto de esta fluidez y de esta consideración «siempre abierta» de riesgos es su formulación multifactorial, tendencialmente inagotable, de modo que también las intervenciones de previsión deben tener una articulación compleja en varios planos.

Con atención a otros aspectos, algunas/os autoras/es han inscrito las prácticas contemporáneas de gobierno del riesgo en un marco de gobernabilidad reflexiva ${ }^{84}$. Esta noción se refiere a un desplazamiento de los dominios y objetivos del gobierno desde la regulación de los procesos económicos y sociales exteriores, como medio de provisión y mantenimiento de la seguridad, al aseguramiento de los mecanismos de regulación de esos procesos exteriores en sí mismos. Un modo de atender este nuevo objetivo es asegurar que los mecanismos de regulación tengan una forma coherente con los objetivos últimos de gobierno y que promuevan una conducta, individual e institucional, que sea asimismo armónica con esos objetivos. Es decir, que sean capaces de vincular una regulación de la conducta funcional con la estandarización de todos los mecanismos de regulación del riesgo, dispersos, locales y especializados, de modo que sea posible un gobierno de toda esa multiplicidad con el establecimiento de unidades eficaces pero también estables y gobernables entre los sistemas de mercado, de servicios y de expertos ${ }^{85}$.

La seguridad dependerá, por tanto, de la capacidad de consolidar esa pluralidad de unidades de gobierno con carácter estable, de asegurar su eficacia respecto a los objetivos

\footnotetext{
${ }^{82}$ BAKER, T. «Risk, insurance, and the social construction of responsibility», Embracing risk: the changing culture of insurance and responsibility, en en T. Baker y J. Simon (eds.), Chicago; London, The University of Chicago, 2002, p. 33-5I (pág. 42).

${ }^{8}$ ROSE, N. «Authority and the genelogy of subjectivity», Detraditionalization: critical reflections on authority and identity, en P. Heelas, S. Lash \& P. Morris (eds.), Oxford, Blackwell, I996, p. 294-327.

${ }^{84}$ ASHENDEN, S. «Reflexive governance and child sexual abuse: liberal welfare rationality and the Cleveland Inquirty».Economy and Society,25(I), I996, p. 64-88. Y M. Dean, Governmentality: power and rule in modern society, cit. págs. I72-176.

${ }^{85}$ Con el objetivo de concretar esta idea, observamos que en el campo de la protección de la infancia, MUNRO, E. Munro, Eileen «Learning to reduce risk in child protection», British Journal of Social Work,40(4), 20IO, p. II35-II5I (pág. II45) distingue los «riesgos sociales» (en este caso, de maltrato y desamparo de los/as niños/as) de los «riesgos institucionales», en cuanto a la posibilidades de que operadores y agencias se vean criticadas y perjudicadas por malas valoraciones de riesgos, ausencia de actuaciones o intervenciones excesivas. Ello permite observar en qué ocasiones, las estrategias de las agencias se dirigen más a evitar los riesgos institucionales, por ejemplo derivados de la ausencia de intervención en un caso que resulta con lesiones graves para el/la menor, que los sociales o exteriores, por ejemplo derivados de situaciones de negligencia menos graves pero mucho más numerosas.
} 
propuestos y de establecer asimismo unas relaciones fiables en el continuo que va desde los órganos superiores hasta sus usuarios, lo que permitirá sedimentar una autoridad respecto a los gobernados.Por tanto, los desplazamientos para un régimen de prácticas de gobierno, en este caso de la seguridad, no se producen solo en el plano de su orientación, sino también a partir de distintas innovaciones técnicas interconectadas, de las que queríamos destacar algunas. M. Dean ${ }^{86}$ expone dos conjuntos de tecnologíasque tomamos aquí por su funcionalidad respecto a la gestión de la incertidumbre en las sociedades de control ${ }^{87}$. Éstas son las tecnologías de agencia y las tecnologías de rendimiento o de resultados(performance). En un trabajo muy influyente, Power ${ }^{88}$ también ha subrayado la inserción de estas tecnologías de control interno o de auditoría, en sentido amplio, dentro de los muy diferentes marcos de governance, donde contarían con funciones relevantes en la formación de un saber reconocido como válido y útil para la regulación de estos sectores de actividad, muchas veces encargados de gestionar diferentes riesgos sociales, así como para el fortalecimiento de la confianza ciudadana en la capacidad y transparencia de estos mecanismos.

Las tecnologías de agencia se dirigen a aumentar la capacidad de vinculación e intercambio de los individuos y grupos. M. Dean alude a la existencia de dos grandes tipos de estas tecnologías. De una parte, las que permiten hablar de un «nuevo contractualismo» a partir de la proliferación de un tipo de acuerdos en todos los órdenes: desde las Administraciones que financian los servicios públicos a las entidades privadas que los prestan, acuerdos en el interior de las empresas y las escuelas, para la búsqueda de empleo, etc. Ello supone la re-legitimación de las tecnologías de contractualización, con las posibilidades y problemas que han presentado históricamente. La literatura postfoucaultiana reconoce muchas de estas tendencias en los regímenes de prácticas de regulación de las dinámicas económicas y sociales que devinieron hegemónicas en el ámbito anglosajón desde los $1980 \mathrm{~s}^{89}$.

Un segundo tipo que M. Dean distingue dentro de estas tecnologías de agenciason las tecnologías de ciudadanía, que buscan la aparición y la representación de la voluntad de los usuarios y consumidores como medio para incluir esas necesidades y deseos en sus programas yhacerlos partícipes. Ejemplos de ello pueden verse en las estrategias de desarrollo comunitario, en los estudios de impacto ambiental o social, en los procesos de participación, en las campañas de salud pública y en la expansión de un tipo de gobernabilidad diferencial o gobierno de la diferencia y de línea de modernización de las agencias de gobierno denominada «nueva gestión pública» (new publicmanagement ${ }^{9 \circ}$ ). Muchas de estas tecnologías se orientan a grupos definidos por su situación de riesgo (targetedgroups), con el objetivo de incrementar su capacidad de auto-gobierno en esas tareas de previsión.

Además, las tecnologías de rendimiento tienen un efecto notable sobre los sistemas de expertos para la gestión de riesgos, que habían sido bastante impermeables durante el welfare, y la subsunción de esos dominios materiales expertos en unos nuevos regímenes formales de cálculo, funcionales a los regímenes de prácticas contemporáneos: por ejemplo, haciendo comparables y optimizables las tecnologías de agencia, controlando sus

\footnotetext{
${ }^{86} \mathrm{M}$. Dean, Governmentality: power and rule in modern society, cit. págs. I67-I70

${ }^{87}$ DELEUZE, G. «Post-scriptum sobre las sociedades de control», en Conversaciones: I972-I990 (J. L. Pardo, trad.), $4^{a}$ edición en castellano, Valencia, Pre-Textos, 2006, p. 277-286.

${ }^{88}$ POWER, M. The Audit society: rituals of verification, $\mathrm{I}^{\mathrm{a}}$ reimpresión, Oxford, Oxford University Press, I999, págs. 8-II.

${ }^{89}$ Rose, Governing economic life, cit. págs. I4-8. Y GILBERT, N. «US welfare reform: rewritting the social contract», Journal of Social Policy,38(3), 2009, p. 383-399 (pág. 389).

${ }^{\circ}$ CLARKE, J. «New Labour's citizens: activated, empowered, responsibilized, abandoned?», Critical Social Policy,25(4), 2005, p. 447-463.OSBORNE, D. y GAEBLER, D. La reinvención del gobierno: La influencia del espíritu empresarial en el sector público, (M. A. Galmarini y F. Pardo Gella, trads.) I a reimpresión en castellano, Barcelona, Paidós Ibérica, I995.
} 
resultados, etc ${ }^{9}$. Al intervenir sobre estas formas de institucionalidad y de organización bastante generalizadas durante la expansión del Estado del bienestar, estas tecnologías han dibujado un rápido ascenso en ámbitos en principio alejados de las políticas de seguridad, como las agencias de policía ${ }^{92}$, o en distintos ámbitos del gobierno social ${ }^{93}$. Al igual que ocurre con los discursos de riesgos, la vaguedad y amplitud en las definiciones y ejercicios de estas tecnologías resulta una característica decisiva para su adaptabilidad y su actual expansión ${ }^{94}$.

En su funcionamiento combinado, estas nuevas tecnologías hacen eficaces algunas estrategias que pueden encuadrarse en un marco de gobierno a distancia ${ }^{95}$. Por ejemplo, el despliegue de esas tecnologías neo-contractuales permite el establecimiento de numerosos centros de auto-control del riesgo, cuya dispersión y multiplicidad imprescindibles pueden mantenerse, sin embargo, dentro de parámetros gobernables, a través de las tecnologías de rendimientos, que subsumen estos centros locales en una racionalidad centralizada y superior: véanse las decisiones sobre el control presupuestario, las reglas de administración, las técnicas de auditoría y evaluación, etc. Así y desde los I990s, la actividad de gobierno ha optado menos por el establecimientode reglas de conducta y más por mejorar el ensamblaje y la articulación de las distintas agencias y operadores, en un trabajo en red, a partir de la producción interna de auto-vigilancia, confianza y autoridad; lo que permite cierta eficiencia respecto a los proyectos comunes, así como mantener el tratamiento específico de cada actividad ${ }^{96}$. Así, resulta evidente que, en este contexto de gobierno a distancia y mayor auto-regulación, las funciones del derecho en la regulación de estos riesgos se desplazan desde una regulación exterior a partir de reglas sustantivas, hacia una regulación más adjetiva, sobre todo centrada en los marcos y técnicas que permiten el funcionamiento de esas prácticas de auto-gobierno y de gobierno a distancia ${ }^{97}$.

\section{La gestión de la crisis económica de 2008 desde la perspectiva de la regulación del riesgo}

En los Estados del Sur de Europa, no es difícil percibir el gobierno de la situación de crisis económica desde 2008 como un cambio en los regímenes de regulación de riesgos respecto a sus antecedentes en la última parte del siglo XX y la primera década de los 2000. En los siguientes apartados, analizaremos las propuestas que pueden deducirse del enfoque de la sociedad de riesgos ante esta situación y profundizaremos en nuestras aportaciones hacia un marco analítico alternativo para el análisis de los regímenes de regulación del riesgo, con la vista puesta en los cambios en curso y en las posibilidades que se dibujan para gobernar la incertidumbre de un modo más eficaz respecto a los intereses del conjunto del

${ }^{9}$ II ROSE, N. \& MILLER, P. «Political power beyond the State: problematics of government», The British Journal of Sociology,43(2), I992, p. I72-205.

$9^{92}$ Ericson en Valverde, Radically rethinking regulation, cit. y ERICSON, R. V. y HAGGERTY, K. D. (2007) «El control policial del riesgo», Delito y Sociedad,I6(24), 2007, p. 27-6I, (trad. M. Narváez).

${ }_{93}$ Vid.Parton (I996, III-2). Rose et al. $(2006,93)$ dan cuenta del desarrollo de ciertos enfoques centrados en esta emergencia de tecnologías de agencia, rendimientos y gobierno a distancia, que sobre todo ponen atención en el método y realidad del funcionamiento detallado de las agencias y comportamiento de los operadores, como la science and technologicalstudies y la actor network theory, que tienen una vía de conexión con los planteamientos foucaultianos a partir de algunos autores como Latour (2007).

94 Power, The Audit society: rituals of verification, cit., págs. xviii y 6-7.

${ }^{95}$ Rose y Miller, Governing economic life, cit.; y Rose y Miller, Political power beyond the State, cit.

${ }^{96}$ Rose y Miller, Governing economic life, cit.págs. 9-II.

${ }^{77}$ Puede ampliarse esta cuestión en Ericson, El control policial del riesgo, cit. págs. I7-I9 o en

FEBBRAJO, A. «For a socio-legal theory of risk», Sociologia Del Diritto,2, 2009, p. 69-9I (págs. 69-70), que toma como referencia, para aproximaciones y críticas, la perspectiva luhmanniana. 
cuerpo social y de los grupos vulnerables, que por otra parte se encuentran en franca expansión.

IV.I. La sociedad del riesgo para el análisis de los cambios en la gestión de la incertidumbre: límites de la intuición

En los I990s, las perspectivas de la sociedad del riesgo fueron capaces de expresar con acierto una sensación paradójica y bastante vergonzante referida a la intensificación de distintas formas de exposición a la incertidumbre respecto a diferentes grupos de población justo cuando la historia se daba por cerrada y, al menos en las sociedades aparentemente hegemónicas, solo restaba esperar un futuro de mejoras técnicas y aumentos en los estándares de calidad de vida. Sin embargo, en relación con la actual situación, podemos identificar dos puntos de contraste principales entre nuestra visión de la crisis (o más bien de su gestión) como una crisis de gestión de la incertidumbre y el riesgo y aquellas que pueden deducirse del marco de la sociedad del riesgo y que, no obstante, tienen bastante presencia en el imaginario público acerca de su génesis y de sus vías de solución.

En primer lugar, no puede apreciarse una situación de desregulación de las dinámicas económicas financieras (en el caso español, sobre todo encarnadas en la expansión del ciclo inmobiliario ${ }^{98}$ ) cuya creciente complejización diera lugar a riesgos incontrolados, que habrían estallado principalmente en 2008 dando lugar a un periodo de recesión y empeoramiento de las condiciones de vida.Por supuesto, desde la perspectiva de la prevención de los riesgos económicos sistémicos, puede ponerse el foco en la inexistencia de ciertos límites, mecanismos de equilibrio o en la inacción de distintos agentes reguladores. Sin embargo, en el contexto español, podemos analizar la situación de otro modo. Sí es cierto que la principal fuente de generación de riesgos ha estado ligada al ciclo inmobiliario, tanto por la cantidad de empleo que se ha destruido, por la situación de quienes no pueden hacer frente a las deudas hipotecarias, como por sus efectos sobre la solvencia y estabilidad bancaria y por el citado peso del sector de la construcción. Dicho lo cual resulta difícil afirmar que la dinámica inmobiliaria estuviera puramente descontrolada, sino que es más fácil identificar ciertas estrategias para su refuerzo a través de la articulación de las reformas de la ley del suelo ${ }^{99}$, el favorecimiento del crédito mediante el establecimiento de tipos de interés muy bajos y los sistemas de financiación de las Administraciones Autonómicas y Locales, que asumieron el emprendimiento y la intensificación de este ciclo.Por tanto, existe todo un marco regulador ${ }^{\text {10o }}$ que no desconocía las incertidumbres que se producían en su seno, sino que las seleccionaba y las «prefería» a otras nada menores, como podrían ser las derivadas de las situaciones de estancamiento económico con sus conocidos efectos sobre el empleo, la renta y la propia seguridad del Estado $^{\text {ToI }}$. Ésta es una posición no solo visible en relación con los grandes beneficiarios de

\footnotetext{
$9^{8}$ Desde los I990s, el mercado de activos financieros - inmobiliarios atraía buena parte de la inversión interna y también extranjera, sosteniendo los incrementos del Producto Interior Bruto (en adelante, PIB) y de los patrimonios familiares. Como indican LÓPEZ, I. y RODRÍGUEZ LÓPEZ, E. Fin de ciclo, Madrid, Traficantes de Sueños, 20Io. (p-ag. 202), «entre I995 y 2005, la vivienda ganó más de Io puntos porcentuales en la cifra total de inversión, llegando a representar cerca del $40 \%$ de la totalidad de las inversiones realizadas en el año 2005. Muestra de la sobreespecialización de la economía española en la construcción es que, en ese mismo año, la suma de la inversión en vivienda y en infraestructuras supuso la increíble cifra del 70\% de las inversiones totales».

${ }^{99} \mathrm{La}$ principal, la operada por la Ley 6/1998, de I3 de abril, sobre régimen del suelo y valoraciones (BOE 8788 de I4 de abril de I998). La propia Ley 8/2007, de 28 de mayo, de suelo (BOE IO7OI de 29 de mayo de 2007), que la derogó, reconoció en su Exposición de Motivos los «inconvenientes» que ha causado el anterior sistema de clasificación y categorización del suelo.

${ }^{100}$ Foucault, Nacimiento de la biopolítica, cit. págs. IO2 SS.

${ }^{\text {го }}$ Como indica JESSOP, B. State power: a strategic relational approach, $\mathrm{I}^{\mathrm{a}}$ edición, Cambridge, etc., Polity Press, 2008.(pág. I92), «incluso cuando el Estado neoliberal parece retirarse de la economía de mercado, interviene más en el ámbito extra-económico, subordinándolo a las demandas de valorización».
} 
estas operaciones, sino con su capacidad para hacer depender el resto de indicadores macroeconómicos de la continua expansión del ciclo inmobiliario-financiero. Por supuesto, el correlato de los bajos tipos de interés y del consecutivo aumento de la inversión/deuda privada es, inmediatamente cerrado el periodo de mayores beneficios del ciclo inmobiliario, el aumento de los capitales fugados de la economía española y la progresiva asunción por parte del Estado de esas deudas privadas que quedaron más allá del punto de inflexión, como muestran los sucesivos rescatesde entidades financieras y la nacionalización indirecta de la inversión no realizada en la construcción. En cualquier caso, los perjuicios de las incertidumbres que se fueron generando entre 1996 y 2007 hoy son tan evidentes como la dificultad de imaginar medios distintos para alcanzar el crecimiento económico propio de ese periodo en España.

En segundo lugar y dentro de un enfoque más amplio, hay que descartar que los riesgos funcionen dentro de la racionalidad política (neo)liberal como un mal. Por supuesto, la racionalidad neoliberal no es coherente ni en el plano discursivo, ni mucho menos en la implementación de unos regímenes de prácticas y de unas políticas públicas ${ }^{\mathrm{IO2}}$; sobre todo por su densa hibridación con gubermentalidades neo-conservadoras. A pesar de esta «dificultad», resultan bien visibles estrategias en que el fomento de la incertidumbre sobre determinados grupos y la formalización, digamos con ingenuidad, desequilibrada de los riesgos son vías principales para mantener las tasas de acumulación, crecimiento, empleo y seguridad en general. El ejemplo del ciclo inmobiliario es central en nuestro contexto pero pueden establecerse analogías con procesos más periféricos como la expansión de las industrias de seguridad, de los instrumentos financieros de aseguramiento, de salud o de educación. Todos ellos exigen contextos dominados por incertidumbres relevantes que no encuentran posibilidades de previsión dentro del Estado, de la comunidad o de la familia. En una economía que se ha volcado sobre la vida, son las incertidumbres que acechan determinadas condiciones de vida, así como la formalización empresarial de ciertas vías para su previsión, los terrenos económicos más fértiles. En la gobernabilidad neoliberal, grandes incertidumbres y pequeños riesgos son clave en el funcionamiento de la economía, a veces con beneficio de grupos muy pequeños (como ocurre hoy con los participantes en los mercados de deuda), a veces con beneficios más amplios ${ }^{\mathrm{TO} 3}$, como los que se irradiaron durante los felices 2000 .

\section{IV.2. Sociedad del riesgo y sociedad del crecimiento}

En cualquier caso, el enfoque de la sociedad del riesgo tiene la virtud de proponer una descripción positiva de nuestro presente y de captar el crecimiento, no tanto del riesgo, como de la incertidumbre. En esta tarea, nuestra propuesta es que la gobernabilidad neoliberal opera sobre la incertidumbre y el riesgo como un régimen de veridicción, de definición de una verdad para el gobierno. De este modo, distintos mecanismos integrados en su seno seleccionan ciertas incertidumbres, las formalizan en riesgos y buscan su funcionalización dentro de circuitos de valorización y de acumulación o bien, de contención y exclusión.

En los últimos veinte años, la centralidad del ciclo financiero-inmobiliario coincidió con una transición en los regímenes de regulación de los riesgos sociales desde el llamado welfare al welfaretoworkoworkfare. A partir de la conceptuación anterior, podemos enunciar de manera muy sintética cómo se funcionalizaban los riesgos y las incertidumbres

\footnotetext{
${ }^{\text {Io2 }}$ HARVEY, D. A brief history of neoliberalism, $\mathrm{I}^{\mathrm{a}}$ reimpresión, Oxford, etc., Oxford University Press, 2007 (pág. I9).

${ }^{103}$ Según la Encuesta Financiera de las Familias del Banco de España, entre 2002 y 2005, el patrimonio medio de las familias aumento cerca de un 50\%, de I67.000 euros a más de 250.000 euros; siendo de carácter inmobiliario más del 80 \% del valor del patrimonio resultante(López, Fin de ciclo, cit., pág. 240).
} 
en este esquema. Para Taylor-Gooby ${ }^{\mathrm{I} 4}$, este marco tiene las siguientes características regulativas. Primero, desregulación del mercado, de las condiciones de trabajo y de diversos espacios de la economía global. Segundo, centralidad del empleo en las políticas sociales, expresada en distintos enfoques de las políticas de activación y de las políticas sobre la pobreza $^{\text {Ios }}$. Tercero, adelgazamiento de las prestaciones sociales welfaristas que permitían a sus destinatarios mantenerse fuera del mercado de trabajo (incapacidades temporales, prejubilaciones, etc. $)^{\mathrm{I0}}$. Cuarto, un mayor uso de las políticas asistenciales, en particular de las políticas de rentas mínimas o políticas negativas de renta y, sobre todo, de las dirigidas a grupos considerados de alto riesgo, como jóvenes con escasa cualificación profesional, familias monoparentales y familias con hijos e ingresos escasos. Y por último, un diseño e implementación conforme a los esquemas de «nueva gestión pública» (new publicmanagement).

En España, la vía de expresión más clara de estos enfoques han sido las políticas de activación ${ }^{\text {Io7 }}$, dirigidas a revertir la situación de «dependencia» de ciertos grupos a través de su integración en el mercado laboral o, al menos, de su puesta en disposición de emplearse ${ }^{108}$. A ello se une la previsión de incentivos, tanto fiscales como sociales, conectados con el ejercicio efectivo del empleo o con la disposición activa a alcanzarlo.

La eficacia específica de estas políticas de activación ha sido muy discutida ${ }^{\mathrm{I0} 9}$ pero, en conjunto, la articulación entre el ciclo financiero-inmobiliario y estas políticas sociales workfaristas dieron lugar a un aumento fortísimo de las tasas de empleo y sobre todo de actividad, en particular respecto a jóvenes, mujeres y extranjeros/as. También dieron lugar a un periodo de mejora de los indicadores macroeconómicos con pocos precedentes y se sostuvieron sobre un consenso social abrumador, aunque seguramente difícil de confirmar hoy, a la vista de los resultados.

Desde la perspectiva de la regulación de riesgos, lo interesante es ver cómo el riesgo implícito en esas operaciones financieras-inmobiliarias pudo ser funcionalizado, en el interior de políticas sociales workfaristas, durante un periodo bastante prolongado,con la posibilidad de que las clases altas obtuvieran fuertes beneficios pero también en favor de las estrategias de ahorro e inversión de las clases medias y, en general, de las dinámicas de crecimiento económico y creación de empleo, incluso con la expansión (bastante tímida) de

I04TAYLOR-GOOBY, P. Reframing social citizenship, Ia edición, Oxford, Oxford University Press, 2009 (págs. 38-4I Y II5-II9).

${ }^{105}$ PROCACCI, G. «Genealogies of poverty: From inclusion towards exclusion», Development,5०(2), 2007, p. 26-30, ofrece una interesante evolución de la noción de pobreza dentro de las políticas públicas desde los i970s.

${ }^{106}$ Sea a través de la restricción de estas ayudas o del fomento de las prestaciones condicionadas al empleo, la idea de «hacer que el trabajo compense» aún puede verse en documentos oficiales como el de la COMISIÓN EUROPEA The future of the European employment strategy. A strategy for full employment and better jobs for all. Bruselas, Oficina de Publicaciones de la Comisión Europea, 2003.

Io7 Vid.TAYLOR-GOOBY, P. «Paradigm shifts, power resources and labour market reform», Ideas and welfare state reform in Western Europe, en P. Taylor-Gooby (ed.), Houndmills, Ed. Palgrave Macmillan, 2005, p. I2-29 o AUST, A. y ARRIBA, A. «Toward activation? Social assitance reforms and discourses», Ideas and Welfare State reform in Western Europe, en P. Taylor-Gooby (ed.), Houndmills, Ed. Palgrave Macmillan, 2005, p. IOO-I23 (págs. IO7-III), para distintos contextos.

${ }^{108}$ Vid. Clarke, New Labour's citizens, cit., págs. 452-453. LEWIS, P. «Upskilling the Workers will not Upskill the Work. Why the Dominant Economic Framework Limits Child Poverty Reduction in the UK», Journal of Social Policy, 40, 3, 20II, p. 535-556 (págs. 538-539), entre otros, ha concretado las políticas familiares británicas en esta dirección: obligación genérica de una búsqueda activa de empleo. Para determinados grupos con mayores dificultades, participación en programas de activación más específicos. Y, por último, una mayor individualización de las condiciones de las prestaciones para determinados sujetos en situación de desempleo de larga duración.

Io9 Ver para ello, MORENO MÁRQUEZ, G. Crisis y reconstrucción del Estado del Bienestar: las posibilidades de la Renta Básica de Ciudadanía, Vitoria-Gasteiz: Ed. Servicio Central de Publicaciones del Gobierno Vasco, 2008 (caps. 2 a 4 ). 
ciertas previsiones sociales en el periodo $2005-2009^{\text {IIO }}$. En este proceso, incertidumbres como las propias de este mercado laboral, que consolidó artificialmente la expectativa de un aumento constante del precio de la vivienda que aseguraba la rentabilidad de cualquier inversión, por alta que fuera; o las relativas a un futuro posterior a los $6_{5}$ años sin una vivienda en propiedad, animaron más que retrajeron estos circuitos; sin contar con que los productos hipotecarios de mayor riesgo (las conocidas hipotecassubprime, en referencia a su calidad) fueron algunos de los productos financieros más rentables. Por tanto, en un contexto consolidado de capitalismo financiero, la sociedad del riesgo se ha mostrado también como la sociedad del crecimiento.

IV.3. Nueva gobernabilidad post-workfarista: incertidumbre y riesgo sin crecimiento ni empleo

Sin embargo, distintos indicios apuntan de manera muy consistente hacia la hipótesis del fin de esta articulación entre el circuito financiero-inmobiliario y las políticas sociales workfaristas $\mathrm{y}$, por tanto, a toda una reconfiguración de los mecanismos de funcionalización del riesgo y de producción de incertidumbre. Hipótesis que, a su vez, instaría a pensar la gobernabilidad social contemporánea con grandes distancias respecto a la gobernabilidad welfarista, hegemónica desde el final de la II Guerra Mundial(aunque con distintos niveles de implantación), pero también respecto a la gobernabilidad workfarista consolidada desde los ig80s.

Desde luego, ésta es una discusión importante que no puede cerrarse aquí: más que inaugurar palabras, se trata de identificar qué características concretas definen el presente de manera diferencial. En este sentido, la hipótesis de la crisis del welfaretoworkpuede derivarse de dos niveles de debilidad. Uno ha sido muy señalado, en cuanto a los límites en la capacidad aseguradora y la estabilidad del empleo creado, sobre todo en contraste con el empleo típico fordista ${ }^{\text {III }}$. Esto ha reforzado las visiones críticas del welfaretowork, que ya vinculaban la generación de empleo desde finales de los I99os al ciclo alcista de la economía y no a la eficacia específica de estos programas. De hecho, la literatura especializada ${ }^{\mathrm{II}}$ muestra mejores resultados en contextos donde se implementaron políticas complementarias, con servicios de apoyo, complementos de renta o incentivos fiscales; es decir, donde se salieron de sus formulaciones estrictas.

En un segundo nivel de debilidad, las políticas de restricción del gasto social, que han prevalecido como medios para alcanzar los objetivos de solvencia desde 20I0, han impactado de forma decisiva sobre los rasgos vertebrales de estas políticas. En el caso español, esto resulta claro en tres líneas de actuación, de nivel e importancia muy distintos. Con carácter más general, la restricción del gasto y la inversión pública ha afectado de forma sensiblea la capacidad de las Administraciones Públicas para generar empleo, directo e indirecto. Y esta capacidad, pese al mal encaje que tienen en los discursos liberales de activación, había sido fundamental en la declinación práctica de las políticas sociales del welfaretowork en la Europa Continental, en especial en los contextos con menor dinamismo en la creación de empleo, como las economías sureuropeas. A esto hay que sumar la

IIo NAVARRO, V. y REYNOLDS, J. «La inversión en protección social en España en el contexto de la Unión Europea. El reto del déficit social», La situación social en España, en V. Navarro (ed.), Madrid, Biblioteca Nueva y Fundación Largo Caballero, 2009, p. 3I-I36.

${ }^{\text {III }}$ En el caso español y según la Encuesta de Población Activa, la tasa de paro pasó de 7,95 en el IIT 2007, a 25, 02 en el tercer trimestre de 2012 (fuente: Instituto Nacional de Estadística, en adelante INE).

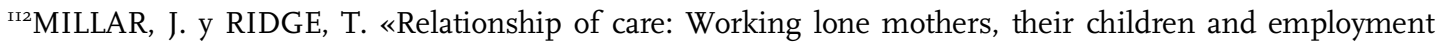
sustainability», Journal of Social Policy,38(I), 2009, p. IO3-I2I.RIDGE, T. y MILLAR, J. «Following families: Working lone-mother families and their children», Social Policy and Administration,45 (I), 20II, p. 85-97. Entre otras muchas. 
retracción de las políticas activas de empleo ${ }^{\mathrm{II}}$, típicas de estos enfoques, en su contraste con las welfaristas políticas pasivas de empleo y de ciertas medidas de conciliación de la vida familiar y laboral, que podían servir para incentivar la disposición al empleo ${ }^{\text {II4 }}$.

Desde la perspectiva de la seguridad, la quiebra del esquema del welfaretoworkafecta de manera decisiva al núcleo de la gobernabilidad liberal-welfarista, centrado en el mantenimiento de un circuito que ligaba la buena marcha del mercado (expresado en forma de crecimiento económico) con aumentos en la creación de empleo formal, así como de los salarios y de las protecciones directas o indirectas ligadas a esos empleos.Aunque los esquemas neoliberales y workfaristashabían tensionado este circuito, que tampoco fue nunca ni perfecto ni universal, tanto el gobierno de lo económico como el gobierno de lo social conservaban estos parámetros de seguridad.

Sin embargo, en el presente, la evolución de los Estados del Sur de Europa perfila una nueva gobernabilidad en la que, durante periodos muy prolongados de tiempo, se combinan caídas de los indicadores que miden el crecimiento, el empleo y los ingresos y protecciones de distinto tipo ligadas a éste. Por el momento, los discursos producidos en el interior de esta gobernabilidad liberal califican este tratamiento de la seguridad como transitorio, a la espera de relanzar el circuito anterior, más o menos modificado ${ }^{\text {III }}$.

Desde luego, no compete a este artículo analizar los motivos de la inadecuación de estos programas respecto a la situación de los Estados del Sur de Europa ${ }^{\text {II }}$. Sin embargo, al

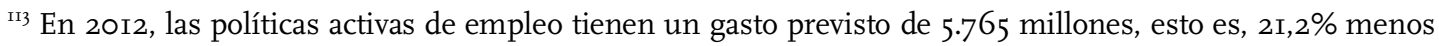
respecto a 20II, que se suma al descenso del $5,5 \%$ de ese año. Solo la partida destinada a bonificaciones ha tenido un incremento del 6,I\% respecto a 20II. En los presupuestos de 20I3 (total de 3.77I,5I millones), se prevé una reducción del $34 \%$, de la que solo se mantiene la partida destinada a formación. El resto cae de forma muy notable, sobre todo por la reducción de las bonificaciones para la contratación y la previsión del fin del Plan PREPARA $(400 €$ y obligaciones de formación para personas paradas con cargas que hayan agotado las prestaciones por desempleo) en febrero de 2013 .

${ }^{\text {II4 }}$ Valga de ejemplo la suspensión en 20II de la entrada en vigor de la ampliación del permiso de paternidad de dos a cuatro semanas, que había sido aprobada por Ley 9/2009, de 6 de octubre (BOE I5958 de 7 de octubre de 2009) o el descenso en el gasto en el tramo educativo de o a 3 años, si bien esto es muy desigual entre distintas CC.AA. y aun provincias. Por ejemplo, en Aragón, los convenios del Gobierno Autonómico con los Ayuntamientos para financiar estas escuelas se redujeron un 35\% entre 20 II y 2012 y se prevé una reducción del 75\% del presupuesto de 2012 para 20I3 (Heraldo de Aragón, 7-II-20I2, p. 3).

${ }^{\text {II }}$ BOYER, R. «The four fallacies of contemporary austerity policies: The lost keynesian legacy».Cambridge Journal of Economics, 36(I), 20I2, p. 283-312, ha analizado recientemente los discursos favorables a estas políticas de reducción del gasto público y de los ingresos salariales e indirectos. Tales políticas se apoyan en el éxito de programas similares en México a finales del siglo XX, Dinamarca (I983-1986), Irlanda (I987-I989), Finlandia (I992-I998), Suecia (I993-I998) y sobre todo en Alemania a inicios del siglo XXI. Para profundizar en el análisis de estos supuestos, ver tambiénPEROTTI, R. «The 'Austerity myth': Gain without pain? », Working Paper, IGIER-Bocconi University, CEPR and NBER, 20II, p. I-57 (disponible en http://www.bis.org/events/confiı623/perotti.pdf; fecha de consulta: I5.II.20I2). En estos ejemplos y de manera sintética, el efecto negativo de la austeridad sobre la economía viene compensado por tres vías. Primero, la reducción de los préstamos e inversiones estatales favorecería el incremento de los préstamos e inversiones privadas, dada la relación de relativa competencia que tendrían con el Estado en el acceso al crédito. Segundo, este saneamiento de las cuentas públicas favorecería la estabilización de las expectativas de los agentes privados, que no tendrían motivos para temer futuras subidas de impuestos $u$ otras inestabilidades debidas al déficit público. Y tercero, la reducción salarial y del gasto público perjudicaría la posición de los trabajadores y aumentaría así la competitividad de las empresas, que podrían incrementar sus exportaciones y mejorar la balanza comercial del país (Boyer, The four fallacies of contemporary austerity policies, cit., págs. 298-299); mecanismo aun más fuerte si existen posibilidades de devaluación monetaria.

${ }^{\text {II6 }}$ En resumen, el mismo Boyer The four fallacies of contemporary austerity policies, cit. se centra en tres razones de ineficacia para el supuesto español e irlandés. Primero, la causa de la crisis no está en el déficit público, sino más bien en la situación reciente del crédito privado al final del boom financiero. Segundo, los tres canales de compensación de los efectos restrictivos de las políticas de austeridad citados antes no operan en estos casos, dado que los contextos son muy distintos a aquellos en que tuvieron éxito. Y tercero, el mencionado éxito en otros contextos, como el alemán, minusvalora la interdependencia de las distintas economías nacionales (por ejemplo, el crecimiento de las exportaciones alemanas solo fue posible gracias al nivel de endeudamiento de sus Estados clientes en esa época) y la tendente fragilidad del orden político internacional ante situaciones de grave crisis en ciertos Estados. 
considerar los efectos de estos programas sí cobra fuerza la hipótesis de llegar a asistir a un largo periodo de gobernabilidad post-workfarista o de gobernabilidad al margen del empleo y del crecimiento.

Desde la perspectiva de gobierno, éste es un cambio notable en lo que podríamos llamar con laxitud la episteme del gobierno social y en el rol previsor del Estado, que sobre todo interesa por su impacto sobre el pensamiento actual de la acción de gobierno. Es decir, $\mathrm{su}$ efecto respecto a la configuración de los saberes de gobierno y los marcos epistémicos dentro de los que se validan y se priorizan distintas acciones de gobierno ${ }^{\mathrm{II}}$. Éste es un plano de repercusión de los cambios poco reconocido pero fundamental para poder analizar las grandes transformaciones en curso.

Respecto al Estado y a su rol asentado en la gobernabilidad social, las proyecciones solo pueden ser ambivalentes. Por un lado, esta reorientación de los criterios de gobierno desplaza también el sentido de su intervención y destituye a la «economía nacional» como el plano privilegiado de validación económica y gubernativa, en favor de planos supraestatales propios de economías fuertemente financiarizadas $y$, en general, de la globalización. Para nuestro enfoque, lo relevante no es tanto la pérdida de soberanía, en su sentido clásico, como la pérdida de sintonía entre los principales indicadores económicos nacionales y los principales indicadores de la marcha de la economía. El desplazamiento de estos últimos, como se ha mostrado, parece iniciar una línea de divergencia entre la buena marcha del Estado, conforme a los criterios que habían servido hasta ahora, y la buena marcha de la economía, conforme a estos nuevos criterios de seguridad. En cierto sentido, el trabajo científico-social de los próximos años no podrá eludir la tarea de re-sintonización entre esos polos, con atención ineludible al aseguramiento de unas buenas condiciones de vida para la población.

Ahora bien, el rol del Estado es ambivalente en esta nueva gobernabilidad porque el estatal sigue siendo un plano de estructuración política y económica privilegiado y su participación en él, prioritaria. Por ejemplo, esto se expresa mediante unos mecanismos electivos, legislativos y ejecutivos que siguen siendo estatales, de unas situaciones económicas y sociales que continúan declinándose con bastante especificidad en cada Estado y de un fuerte vínculo emocional con sus poblaciones. Dada la conservación de esta relevancia, se abre la incógnita de cómo pueda afectar la reducción de su papel previsor y provisor ante los distintos riesgos sociales. En cualquier caso, esta consideración del Estado es menos paradojal si su tratamiento se desplaza desde las pre-nociones liberales hacia consideraciones más biopolíticas, que tienen detrás ya más de doscientos años de asentamientos y mutaciones en las funciones providenciales del Estado ${ }^{\text {II8 }}$.

La recuperación de la distinción foucaultiana en el seno de la gobernabilidad entre los polos de la ley-sistema de derecho y del orden-sistema administrativo ${ }^{\text {II9 }}$ puede dar buena idea del actual desplazamiento del agente estatal hacia el terreno del Ejecutivo, en contraposición con la clásica centralidad del Poder Legislativo. Aunque animado también por otras cuestiones, éste ha sido un contexto favorable a los debates sobre un nuevo excepcionalismo en la intervención del Estado. Para nosotros es notable (y está siendo objeto de investigación) el impacto que este cambio en la gobernabilidad implica respecto a los métodos jurídicos de expresión y articulación de esta acción de gobierno pero la alusión a la excepcionalidad, fuertemente connotada, suele suponer una frontera a las posibilidades de análisis: la normalidad se analiza y la excepcionalidad se denuncia parece ser el medio de

${ }^{\text {II7 }}$ Rose, Governing economic life, cit.

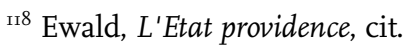

in FOUCAULT, M. «The political technology of individuals» Technologies of the self: a seminar with Michel Foucault, en L. H. Martin, H. Gutman y P. H. Hutton (eds.), Amherst, Massachusetts, University of Massachusetts Press, I988, p. I45-I62 (págs. I60-I62). 
hacer desaparecer los rastros de normalidad (y por tanto las posibilidades de análisis) que existen en cualquier excepcionalidad. Pensar en la posible consolidación de un escenario de gobernabilidad al margen del empleo y del crecimiento permite avanzar en la estandarización y la formalización de lo que hasta hace cinco años era excepcional en nuestro contexto.

Antes mostramos cómo distintos autores definían el tratamiento de los riesgos en el presente dentro de un marco de gobernabilidad reflexiva, en alusión al principal interés de este pensamiento y acción de gobierno por conservar las condiciones principales del escenario de partida. Puesta la cuestión en términos de orden, la seguridad interna de los propios espacios de gobierno ha sido un objetivo constante ${ }^{\mathrm{I2}}$. Pero sí es más novedosa la creciente desconexión entre estos objetivos de orden interno y la consecución de ciertos logros exteriores, como los que componían el programa de mejora de las condiciones de vida durante el welfare. Al hablar de un escenario de gobernabilidad reflexiva, tratamos de un escenario en que ha aumentado la interiorización y la funcionalización de los riesgos en la dinámica de gobierno.

Por ejemplo, se trata de un escenario en que aumentan las posibilidades de ganancia financiera a través de la deuda incluso en contextos de empeoramiento de los principales indicadores macroeconómicos y con bastante desconexión respecto a las remuneraciones más generalizadas en forma de salario, de prestaciones sociales o de rentas derivadas de bienes patrimoniales. De hecho, el tratamiento de la deuda de los Estados ha sido un instrumento privilegiado de funcionalización de ciertos riesgos en el interior de los mercados financieros, que es obvio pueden tener consecuencias muy serias sobre la estabilidad de estos Estados y las condiciones de vida de sus poblaciones. En particular, desde 20 Io se han producido notables aumentos del precio de los swaps de incumplimiento crediticio de los Estados $^{\text {I2I }}$, que por tanto han definido nuevas relaciones de funcionalidad entre la ganancia financiera y las expectativas de (im)pago de su deuda por parte de los Estados.

En este punto es visible la relevancia de los nuevos mecanismos de gobierno a distancia que señalamos arriba. La expansión de las tecnologías de auditoría y de calificación de las deudas de las distintas Administraciones y entidades privadas desempeñan un rol decisivo en la funcionalización del riesgo y tienen un impacto directo en las posibilidades generales de la población para acceder a ingresos, y a medios para reducir su incertidumbre. Como es obvio, parte de la eficacia de estas técnicas reside en la posibilidad de hacerlas perceptibles como instrumentos técnicos y de escaso posicionamiento político. El Estado se desplaza así desde el principal agente previsor hacia un gestor secundario de lo que $y$ a viene gestionado por los mecanismos de estandarización del riesgo en los mercados financieros. Por tanto, no se asiste aquí solo a un típico movimiento de privatización, en cuanto a relevamiento del Estado en la titularidad de la gestión, sino a todo un desplazamiento del Estado del centro de la gobernabilidad welfarista y workfarista. Correlativamente es difícil de imaginar una «recuperación» estatal de los espacios centrales de la previsión sin una reformulación nada nostálgica de estos canales para el gobierno de la incertidumbre, estas tecnologías y estos agentes en la actividad de gobierno a distancia.

Como corresponde a nuestro esquema de tratamiento del riesgo, se ha vivido aquí una extensa formalización de las dinámicas de endeudamiento de los Estados, que también abre nuevas posibilidades para su problematización, control y gobierno. Evidentemente y

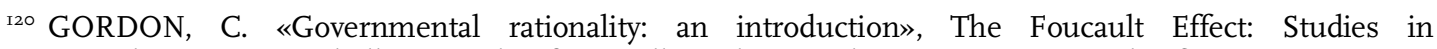
governmentality, en G. Burchell, C. Gordon \& P. Miller (eds.), London, Harvester Weatsheaf, I99I, p. I-5I (pág. 28).

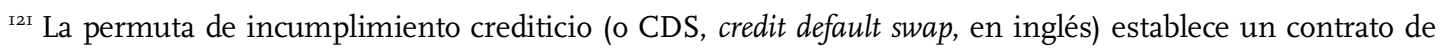
permuta sobre un determinado crédito (en este caso, las deudas soberanas de los Estados) que asegura ese crédito, de modo que su precio depende de las expectativas de (im)pago del Estado en cuestión. 
como constataremos en el apartado siguiente, el tratamiento de estos nuevos riesgos ha tenido más bien efectos de aumentar las condiciones de incertidumbre sobre determinados eventos y capas de población. En cualquier caso, esta creciente autonomía del ciclo financiero respecto a las antiguas «compensaciones» welfaristaso workfaristasdibuja una nueva regla de gobierno difícil de considerar pero a todas luces central.

\section{IV.4. Situación de las poblaciones vulnerables en el marco de la nueva gobernabilidad}

Aunque la consolidación de esta gobernabilidad post-workfarista se produce en un contexto de importantes dificultades e inestabilidades internas, desde una perspectiva de la seguridad como la que presentamos, el límite más claro a su desarrollo proviene de la creciente vulnerabilidad que provoca en determinad grupos de población. Como vimos, cualquier reformulación en el terreno de la gubermentalidad redefine qué incertidumbres se formalizan como riesgos y son destino de recursos para su reducción y compensación y qué otras se decretan intangibles, con la consiguiente exposición de los grupos de población más afectados.

Lo que se pretende aquí es introducir algunas líneas de incertidumbre respecto a las que la regulación de riesgos en la nueva gobernabilidad se hace más apremiante y que constituyen para nosotros terrenos prioritarios de la investigación socio-jurídica. Desde el punto de vista normativo, la crisis de los marcos epistémicos de gobierno desde los que se formulaban y se implementaban las políticas de welfaretoworkpresenta amplias incógnitas acerca de cómo se van a definir los criterios de regulación social capaces de afectar y dotar de seguridad al sistema y a una mayoría de la población. En este sentido, los esquemas de un derecho centrado en la sociedad, es decir, de una producción jurídica ligada a las dinámicas sociales más generales ${ }^{122}$, se hacen difíciles de pensar ante los nuevos criterios que componen los dispositivos de seguridad de lo económico y lo social.

Asumir un periodo prolongado de gobernabilidad sin empleo, sin crecimiento y con restricciones de los ingresos salariales y de las transferencias públicas obliga a desplazamientos en la caracterización de la seguridad liberal: la funcionalización de determinados riesgos, como los derivados de la deuda de los Estados y de los particulares, no permite cubrir progresivamente mayores espacios de incertidumbre respecto a la mayoría del cuerpo social, sino que hoy se asienta precisamente sobre la base de su ampliación. El desajuste entre los estándares de seguridad sistémica y los estándares de seguridad personal y dispositivos de previsión de riesgos habilitaría a rebasar el enfoque de la sociedad del riesgo a fin de alcanzar una sociedad de la incertidumbre.

En el terreno «público», la identificación moderna entre seguridad del orden constituido y seguridad del Estado-nación ha iniciado un proceso de disolución, de manera que la segunda se ha visto desplazada a partir de una generalización de las intervenciones y dispositivos que aseguran el mercado financiero y, con ello, el orden existente. Ahora bien, el aseguramiento de la estabilidad financiera sucede al margen, y hasta en detrimento, del Estado-nación, incluso en el contexto de los Estados centrales ${ }^{\mathrm{I} 23}$. Desde nuestra perspectiva, éste es un cambio decisivo en el enfoque de la gobernabilidad que conviene entender con precisión, ya que el peso del marco estatal sigue siendo muy alto, tanto en sus circuitos de problematización (del desempleo, de la seguridad interna, del crecimiento económico, etc.), como en sus dispositivos de previsión (muchas políticas públicas analizadas tienen sobre todo una dimensión estatal) y en sus marcos de subjetivación (la identidad individual y las

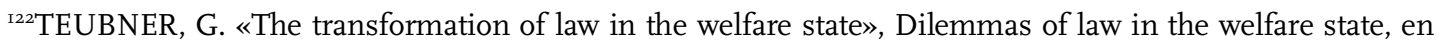
G. Teubner (ed.), Berlin, etc., Walter de Gruyter, I986, p. 3-I2. EWALD, F. «A concept of social law» Dilemmas of law in the welfare state, en G. Teubner (ed.), Berlin, etc., Walter de Gruyter, I986b, p. 40-75.

${ }^{123}$ Es obvio que esto solo tiene sentido desde una perspectiva europea y norteamericana, ya que, mucho antes, el desenvolvimiento de la gobernabilidad moderna ya había puesto en riesgo a numerosos Estados-nación; lo que creemos tampoco resta relevancia a la transformación. 
nociones sociales, así como la opinión y acción política se siguen formulando, en general, dentro de este marco). Pero es un cambio que tampoco conviene desconocer porque altera la gubermentalidad que se había formulado grosso modo desde la segunda mitad del XIX.

En este «terreno público», las repercusiones son claras en sus principales elementos. En las últimas décadas, las políticas sociales que más se han desarrollado han sido aquellas capaces de concretar factores de riesgo ceñidos a la situación particular de determinadas poblaciones. Desde luego, esto ha supuesto notables innovaciones en la previsión y tratamiento de ciertos riesgos sociales y ha mejorado la eficiencia de los recursos respecto a algunas cuestiones definidas como prioritarias. Sin embargo, es importante destacar este giro desde los movimientos de abstracción de los factores de riesgo y sus protecciones en el welfarismo (por ejemplo, para una masa general de asalariados/as, de sus dependientes o de las nuevas generaciones) hacia la concreción de estos factores respecto a determinados grupos vulnerables (grupos excluidos del mercado laboral, con cargas familiares específicas, etc.) y circunstancias de necesidad. En canje de los sistemas (cuasi)universales de previsión por mecanismos de previsión especiales se sitúa plenamente en la línea de traslado del centro de la actividad de gobierno desde el Legislativo al Ejecutivo, a la vez que disuelve los estándares mínimos de satisfacción de los derechos sociales para sujetarlos a los criterios de oportunidad del gobierno. Dentro de la tensión vertebral incertidumbre-riesgo, la primera se habría convertido en la situación normal (salvando lo que pudiera cubrir la auto-previsión) mientras que ciertas incertidumbres anómalas serían cubiertas ad hoc en función de su tolerabilidad y de los trastornos que pudieran suponer para la gobernabilidad.

Desde una perspectiva «privada», la gestión de la crisis ha mostrado bien, en el pinchazo de la burbuja, la diferencia entre qué riesgos se protegen dentro de los sistemas financieros, como posiciones de crédito e instituciones que «no se dejan caer» ${ }^{224} y$ qué otras incertidumbres se dejan al albur de la coyuntura.Evidentemente la situación de incertidumbre de las familias es muy variable, en función de su muy distinta capacidad de auto-regulación y de auto-previsión, lo que se corresponde con una también muy distinta necesidad de obtener previsión por parte de mecanismos abstractos y colectivos, sobre todo estatales. Para las clases altas y quienes en general accedieron con más bienes inmuebles o con más capacidad de inversión y en los primeros momentos del ciclo al mercado inmobiliario, la dinámica de crecimiento con base sobre esos riesgosconstituyó precisamente un dispositivo de seguridad y rentabilidad. Incluso para las clases medias de la época, la estructura de la sociedad de propietarios en España (a imagen de la stakeholdersocietytatcherista) podía funcionar como un medio de aseguramiento de la propia renta, frente al alto precio del alquiler y la necesidad de contar con una vivienda en propiedad en futuro de jubilación con rentas disminuidas y sin ninguna política pública a la vista para alterar estas condiciones del mercado, sino más bien para fijarlas. La situación ha sido muy distinta para las clases bajas que, incluso empleadas, tenían una capacidad de ahorro mucho menor, sobre todo las que entraron más tarde en el mercado inmobiliario $^{\text {125 }}$.En definitiva, la creciente apelación de los discursos de gobierno a la generosidad de las familias con las poblaciones «más necesitadas», junto a su capacidad de auto-previsión: a la búsqueda de planes de pensiones y de salud propios, al ahorro, al esfuerzo, incluso al «sacrificio» y, en general, a una actitud más activa como usuarios de

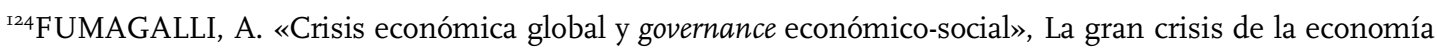
global. Mercados financieros, luchas sociales y nuevos escenarios políticos, en A. Fumagalli, S. Lucarelli, C. Marazzi, S. Mezzadra y A. Negri (eds.), (E. Gatto, trad.), Madrid, Traficantes de Sueños, 2009, p. 99-I23 (págs. III-II6).

${ }^{125}$ Con referencia a la Encuesta Financiera a las Familias del Banco de España, López y Rodríguez, Fin de ciclo, cit., págs. 42I-424 muestran distintos niveles de exposición al riesgo en España, por grupos sociales. En particular, los jóvenes $(<35$ años) se encontraban muy expuestos, incluso en los datos de 2005: considerando situación de alto riesgo la de quien tiene una deuda que multiplica por tres la renta anual disponible, más del $35 \%$ de los jóvenes estaban en esta situación. Después de la crisis, es previsible que también para muchas familias de rentas más altas, el valor de su deuda supere el valor de sus activos. 
unos servicios de previsión ya solo parcialmente estatales, son el corazón pre-moderno (auto-previsión y filantropía) de los sofisticados enfoques de new public management y las políticas sociales más eficientes.

Por otra parte, la gestión de la seguridad desde el ámbito penal tampoco ha reducido su relevancia como medio privilegiado para tratar las fuentes de riesgo atribuidas a determinadas poblaciones. Si bien es cierto que, como muestra la evolución de la población penitenciaria, las nuevas situaciones de incertidumbre no han venido acompañadas de una intensificación de su tratamiento desde el sistema penal(salvo respecto a las dinámicas de protesta ante tales situaciones),el retraimiento de los sistemas de previsión social, abre la posibilidad de que aumente el peso relativo de estos mecanismos de gobierno, formulados más bien desde enfoques de defensa social ${ }^{126}$. En una sociedad de la incertidumbre, una incertidumbre más es que los grandes mecanismos abstractos de regulación social se desplacen desde los seguros sociales y las prestaciones (casi)universales que caracterizaron el welfarismo hacia las modificaciones del Código Penal y las Instrucciones de la Fiscalía General del Estado. En cualquier caso, todavía resultan tan confusos como reversibles los efectos de la incorporación de nuevas masas de población a la pobreza, su impacto en la seguridad sistémica a medio plazo y su tratamiento en uno u otro orden de gobierno.

\section{Conclusión: hacia nuevos regímenes de regulación del riesgo}

En este artículo, hemos partido de los conocidos enfoques sobre la sociedad del riesgo para mostrar distintas cuestiones. Primera, que las perspectivas post-foucaultianas sobre el par riesgo-incertidumbre permiten analizar de forma más útil la evolución en el tratamiento del riesgo, que integra ciertas dinámicas en la producción y externaliza otras incertidumbre sobre las espaldas de ciertos grupos de población, por otra parte, crecientes.

Segunda, que los nuevos regímenes de regulación de riesgos ensayados tras la crisis económica de 2008 han modificado la relación de funcionalidad entre la buena marcha del mercado y la buena marcha de la sociedad y del Estado, iniciando una clara ausencia de sintonía entre los espacios de lo económico y lo social, así como una lógica reconfiguración de esos ámbitos clave en la gobernabilidad. Hemos pretendido subrayar la relevancia de esta transición, introduciendo la noción de sociedad de la incertidumbre para tratar la regulación de estas situaciones en el presente.

Y tercera, que esto ha tenido efectos en distintos órdenes: sobre el Estado-nación, afectando a su centralidad en el gobierno y a la tendencia universalista que dibujaron algunos mecanismos de previsión durante el siglo XX, y, sobre las familias, abriendo nuevos espacios de incertidumbre y de exigencias de auto-previsión.

Como propuestas de investigación, concluimos que, dentro del esquema de evolución de la incertidumbre que hemos presentado, la mejora de la calidad de vida de las poblaciones afectadas, así como un cierto equilibrio sistémico a medio plazo, exigen considerar sus fuentes de incertidumbre, su formalización en factores de riesgo y su atención dentro de dispositivos de previsión de una entidad análoga a los que funcionaron en las etapas centrales de la gobernabilidad social welfarista.

A diferencia de esta etapa, la centralidad de los riesgos financieros para la dinámica económica sitúa, en su regulación, el nudo gordiano de la gobernabilidad social contemporánea, al igual que el empleo industrial fue el objeto de los citados proyectos decimonónicos de articulación de distintas previsiones sociales. Sin embargo y al igual que entonces, no solo se trata de regular los aspectos internos de las dinámicas financieras (minimizar los efectos de las burbujas para las entidades financieras, mejorar la estabilidad

${ }^{126}$ Pitch, ¿Son posibles las políticas democráticas para la seguridad?, cit., págs. 29-30. 
de las entidades de crédito, contener ciertos movimientos especulativos), sino formalizar los riesgos exteriores en que estas dinámicas envuelven a una generalidad de la población, por alejadas que parezcan de los mercados de valores. Al igual que no solo se trataba de regular la relación de empleo industrial, sino de establecer las protecciones para cuando ésta no existía, cuando ya no era posible por edad o enfermedad, así como respecto a las poblaciones que quedaban excluidas de esa relación y atendían las extensas labores de reproducción social.Castel ${ }^{127}$ ya identificó el decaimiento de estos mecanismos de la sociedad salarial en consonancia con el decaimiento del empleo fordista. Veinte años después, podemos ver cómo la gobernabilidad está dando respuesta a los peligros que esta situación supone para su seguridad interna pero a costa de aumentar los espacios de incertidumbre respecto a una cantidad creciente de poblaciones. Analizar estas distintas dinámicas de riesgo y definir los mecanismos de previsión adecuados son, a grandes rasgos, los retos principales de las ciencias sociales contemporáneas. La persistencia que tiene la metáfora del «casino» para definir el funcionamiento actual del sistema financiero global da muestras de un déficit regulativo análogo al que los accidentes industrialestenían durante el XIX, sacándonos de la ciencia para situarnos en el terreno del azar, la superstición o la nostalgia.

En particular, los Estados del Sur de Europa pueden ver muy lesionadas sus instituciones de gobierno social, y por tanto sus capacidades regulativas y previsoras, si las políticas de austeridad continúan implementándose con el rigor que alcanzaron desde 20I0. Las sociedades contemporáneas ofrecen unas oportunidades inéditas para la terciarización de las actividades de gobierno, así como para el ensayo de fórmulas de gobierno complejas o multi-nivel ${ }^{128}$ pero en todas ellas es aún débil la posibilidad de dar sentido a estrategias de gobierno y de regulación tan ambiciosas como las que se requieren hoy. Por otra parte, las propias dinámicas de la acumulación financiera dan la pista de las nuevas fuentes de ingresos públicos, que no pueden seguir recayendo sobre el cuerpo cada vez más reducido y empobrecido de los empleados por cuenta ajena, las actividades económicas de los trabajadores por cuenta propia o el consumo de la generalidad del cuerpo social, toda vez que las apuestas por su intensificación en los dos últimos años dan muestras claras de agotamiento.

Respecto a las familias y los individuos, el establecimiento de nuevos regímenes de regulación de riesgos eficaces pasaría por la reversión de los procesos de (des)regulación en curso. Por una parte, la mayor socialización de la responsabilidad en la actividad de determinación y de previsión ante la incertidumbre, que no puede seguir recayendo de manera creciente sobre poblaciones cuyas capacidades de selección y de prevención se encuentran muy disminuidas, sobre todo si se contrasta con los eficaces y provechosos mecanismos de previsión de riesgos que se han alcanzado en otras dinámicas sociales, como los supuestos de impago, de ralentización de mercados como el inmobiliario o las situaciones de riesgo en los balances de las entidades financieras ${ }^{129}$.

Por otra parte, las políticas sociales deben recuperar universalidad, en contraste con la tendencia a concentrarse en la gestión de coyunturas de necesidad. Como era bien previsible, esta estrategia carece del potencial previsor que tenían los mecanismos de la sociedad salarial. Cerrada esta etapa, la tarea es identificar la participación del conjunto social en los procesos financieros de producción y proteger esas aportaciones, de modo que

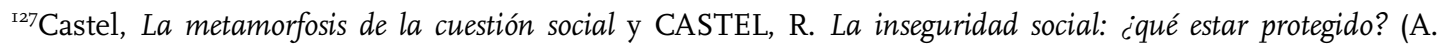
Ackermann, trad.), $\mathrm{I}^{\mathrm{a}}$ edición, Buenos Aires, Manantial, 2004.

${ }^{128}$ JESSOP, B. «Multi-level Governance and Multi-level Metagovernance: Changes in the European Union as Integral Moments in the Transformation and Reorientation of Contemporary Statehood», Multi-level governance, en I. Bache \& M. Flinders (eds.), Oxford, Oxford University Press, 2004, p. 49-74.

${ }^{129}$ Frente a la creciente responsabilización, HartleyDean (2006, I04-5) hace notar la vía abierta por otras políticas sociales en que se ha sido capaz de vincular los problemas sociales a dinámicas y procesos de una dimensión más estructural que el propio comportamiento de los afectados.
} 
no sean hechas en las condiciones actuales de incertidumbre y por tanto de vulnerabilidad. Además, es consistente la doctrina que entiende que solo las tendencias a una protección universal pueden atender estándares mínimos de satisfacción de los derechos sociales ${ }^{130}$, apelando a la incorporación de los saberes jurídicos a estas transformaciones.

\section{Referencias bibliográficas}

ABRAMOVICH, V. «El rol de la justicia en la articulación de políticas y derechos sociales», La revisión judicial de las políticas sociales: Estudio de casos, en In V. Abramovich y L. Pautassi (eds.), Buenos Aires: Ediciones del Puerto, 2009, p. I-89.

ABRAMOVICH, V. y PAUTASSI, L. La medición de derechos en las políticas sociales. $\mathrm{I}^{\mathrm{a}}$ edición, Buenos Aires, Editores del Puerto, 20IO.

ASHENDEN, S. «Reflexive governance and child sexual abuse: liberal welfare rationality and the Cleveland Inquirty».Economy and Society,25(I), 1996, p. 64-88.

AUST, A. y ARRIBA, A. «Toward activation? Social assitance reforms and discourses», Ideas and Welfare State reform in Western Europe, en P. Taylor-Gooby (ed.), Houndmills, Ed. Palgrave Macmillan, 2005, p. IooI23.

BAKER, T. «Risk, insurance, and the social construction of responsibility»,Embracing risk: the changing culture of insurance and responsibility, en en T. Baker y J. Simon (eds.), Chicago; London, The University of Chicago, 2002, p. 33-5I.

BAUMAN, Z. Tiempos líquidos: vivir en una época de incertidumbre (C. Corral, trad.), Iª edición, Barcelona. Tusquets, 2007 .

BECK, U. La sociedad del riesgo: hacia una nueva modernidad (J. Navarro, D. Jiménez y M. R. Borrás, trads.), $\mathrm{I}^{\mathrm{a}}$ edición en col. Surcos, Barcelona, Paidós, 2006.

BOLTANSKI, L. y CHIAPELLO, E. El nuevo espíritu del capitalismo (M. Pérez Colina, A. Riesco Sanz y R. Sánchez Cedillo, trads.) I $\mathrm{I}^{\mathrm{a}}$ edición, Madrid, Akal, 2002.

BOYER, R. «The four fallacies of contemporary austerity policies: The lost keynesian legacy».Cambridge Journal of Economics, 36(I), 2012, p. 283-312.

BRANDARIZ GARCÍA, J. Á. «Nuevos riesgos, nuevas ansiedades y expectativas sociales en materia de seguridad ante el delito», Derecho penal de excepción: Terrorismo e inmigración, en FaraldoCabana, Patricia et al.(eds.), Valencia, Tirant lo Blanch, 2007, p. I39-I60.

C.A.S.E. Collective, «Critical approaches to security in Europe», 20II (disponible en http://www.casecollective.org/; fecha de consulta: I0.4.20II).

CASTEL, R. La metamorfosis de la cuestión social: una crónica del salariado (J. Piatigorsky, trad.), Iª edición, Buenos Aires, etc., Paidós, I997.

ídem; La inseguridad social: ¿qué estar protegido? (A. Ackermann, trad.), $\mathrm{I}^{\mathrm{a}}$ edición, Buenos Aires, Manantial, 2004 .

CLARKE, J. «New Labour's citizens: activated, empowered, responsibilized, abandoned?», Critical Social Policy,25(4), 2005, p. 447-463.

COMISIÓN EUROPEAThe future of the European employment strategy. A strategy for full employment and better jobs for all. Bruselas, Oficina de Publicaciones de la Comisión Europea, 2003

DEAN, H. Social policy. $\mathrm{I}^{\mathrm{a}}$ edición, Cambridge, etc., Polity Press, 2006.

DEAN, M. Governmentality: power and rule in modern society, $\mathrm{I}^{\mathrm{a}}$ reimpresión, London, etc., Sage, 2003.

DEFERT, D. «'Popular life' and insurance technology», The Foucault effect: studies in governmentality, en G. Burchell, C. Gordon y P. Miller (eds.), London, Harvester Weatsheaf, I99I, p. 2II-234.

DELEUZE, G. «Post-scriptum sobre las sociedades de control», en Conversaciones: 1972-I990 (J. L. Pardo, trad.), $4^{a}$ edición en castellano, Valencia, Pre-Textos, 2006, p. 277-286.

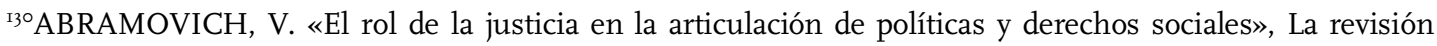
judicial de las políticas sociales: Estudio de casos, en In V. Abramovich y L. Pautassi (eds.), Buenos Aires: Ediciones del Puerto, 2009, p. I-89.ABRAMOVICH, V. y PAUTASSI, L. La medición de derechos en las políticas sociales. $\mathrm{I}^{\mathrm{a}}$ edición, Buenos Aires, Editores del Puerto, $20 \mathrm{IO}$. 
DONZELOT, J. «The mobilization of society», The Foucault Effect: studies in governmentality, en G. Burchell, C. Gordon y P. Miller (eds.), London, Harvester Weatsheaf, I99I, p. I69-I79.

ídem; La Invención de lo social: ensayo sobre el ocaso de las pasiones políticas (H. Cardoso, trad.), I a edición en castellano, Buenos Aires, Nueva Visión, 2007.

ERICSON, R. V. y HAGGERTY, K. D. (2007) «El control policial del riesgo», Delito y Sociedad,I6(24), 2007, p. 27-6I, (trad. M. Narváez).

ESPOSITO, R. Comunidad, inmunidad y biopolítica (A. García Ruiz, trad.), I I edición en castellano, Barcelona, Herder, 2009.

EWALD, F. L'Etat providence, Ia edición, Paris, Bernard Grasset, I986a.

ídem; «A concept of social law» Dilemmas of law in the welfare state, en G. Teubner (ed.), Berlin, etc., Walter de Gruyter, i986b, p. 40-75.

idem; «Norms, Discipline, and the Law», Representations, 30, I990, I38-I6I.

ídem; «Insurance and risk», The Foucault effect: studies in governmentality, en G. Burchell, C. Gordon y P. Miller (eds.), London, Harvester Weatsheaf, I991, p. I97-210.

idem; «The return of Descartes's malicious demon: an outline of a philosophy of precaution» Embracing risk: the changing culture of insurance and responsibility, en T. Baker y J. Simon (eds.) (S. Utz, trans.), Chicago, London, The University of Chicago, 2002, p. 273-30I.

FEBBRAJO, A. «For a socio-legal theory of risk», Sociologia Del Diritto,2, 2009, p. 69-9I.

FOUCAULT, M. El Uso de los placeres. Historia de la sexualidad. vol 2 (M. Soler, trad.), $3^{\text {a }}$ edición en castellano, Madrid, Siglo XXI, I987.

idem; «The political technology of individuals» Technologies of the self: a seminar with Michel Foucault, en L. H. Martin, H. Gutman y P. H. Hutton (eds.), Amherst, Massachusetts, University of Massachusetts Press, I988, p. I45-I62.

ídem; «Omnes et singulatum» Tecnologías del yo. Y otros textos afines, en M. Morey (ed.) (M. Morey, trad.), Barcelona, Paidós, I99I, p. 95-I40.

ídem; «La gubermentalidad. Resumen del curso del Colegio de Francia (I978) «Seguridad, territorio y población»», Obras esenciales. Estética, ética y hermenéutica, en Á. Gabilondo (ed.) (Á. Gabilondo, trad.), Barcelona, Paidós, I999, p. I75-197.

ídem; Nacimiento de la biopolítica. Curso en el Collège de France (1978-1979). Senellart M., Fontana A. y Ewald F. (eds.), $\mathrm{I}^{\mathrm{a}}$ edición en castellano, (H. Pons, trad.), México, etc., Fondo de Cultura Económica, 2007.

ídem; Seguridad, territorio, población. Curso del Collège de France (1977-1978), Senellart M., Fontana A. y Ewald F. (eds.), $\mathrm{I}^{\mathrm{a}}$ edición en castellano, (H. Pons, trad.), Madrid, Akal, 2008.

FUMAGALLI, A. «Crisis económica global y governance económico-social», La gran crisis de la economía global. Mercados financieros, luchas sociales y nuevos escenarios políticos, en A. Fumagalli, S. Lucarelli, C. Marazzi, S. Mezzadra y A. Negri (eds.), (E. Gatto, trad.), Madrid, Traficantes de Sueños, 2009, p. 99-I23.

GARLAND, D. (2003) «The rise of risk», Risk and morality, en R. V. Ericson \& A. Doyle (eds.), Toronto, University of Toronto Press, 2003, p. 48-86.

GIDDENS, A. Consecuencias de la modernidad (A. Lizón, trad.), Ia edición en castellano, Madrid, Alianza, I999.

GILBERT, N. «US welfare reform: rewritting the social contract», Journal of Social Policy,38(3), 2009, p. 383399.

GORDON, C. «Governmental rationality: an introduction», The Foucault Effect: Studies in governmentality, en G. Burchell, C. Gordon \& P. Miller (eds.), London, Harvester Weatsheaf, I99I, p. I-5I.

HACKING, I. «How should we do the history of statistics?», The Foucault effect: studies in governmentality, en G. Burchell, C. Gordon \& P. Miller (eds.), London, Harvester Weatsheaf, I99I, p. I8I-I95.

HAGGERTY, K. D. «From risk to precaution: the rationalities of personal crime prevention», Risk and morality, en R. V. Ericson \& A. Doyle (eds.), Toronto, University of Toronto Press, 2003, p. I93-2I4.

HAMMER, L. M. A Foucauldian approach to International Law. Descriptive thoughts for normative issues, $\mathrm{I}^{\mathrm{a}}$ edición, Aldershot, Ashgate, 2007.

HARVEY, D. A brief history of neoliberalism, I ra reimpresión, Oxford, etc., Oxford University Press, 2007.

HOOD, C., ROTHSTEIN, H. y BALDWIN, R. El gobierno del riesgo: aproximación a los regímenes de regulación de riesgos, (J. Giménez Payrató, trad.), 2ª reimpresión a la Iª edición en castellano, Barcelona, Ariel, 2006.

HUNT, A. «Risk and moralization in everyday life», Risk and morality, en R. V. Ericson \& A. Doyle (eds.), Toronto: University of Toronto Press, 2003, p. I65-192. 
JESSOP, B. «Multi-level Governance and Multi-level Metagovernance: Changes in the European Union as Integral Moments in the Transformation and Reorientation of Contemporary Statehood», Multi-level governance, en I. Bache \& M. Flinders (eds.), Oxford, Oxford University Press, 2004, p. 49-74.

ídem; State power: a strategic relational approach, $\mathrm{I}^{\mathrm{a}}$ edición, Cambridge, etc., Polity Press, 2008.

JONES, T. (2007) «The governance of security: pluralization, privatization, and polarization in crime control», The Oxford Handbook of Criminology, en M. Maguire, R. Morgan \& R. Reiner (eds.), 4 a edición, Oxford, Oxford University Press, 2007, p. 84I-865.

LACRUZ BERDEJO, J. L. y RIVERO HERNÁNDEZ, F. Elementos de Derecho Civil, $3^{a}$ edición, Madrid, Dykinson, 2005 .

ídem; Elementos de Derecho Civil, $4^{\mathrm{a}}$ edición, Madrid, Dykinson, 2007.

LATOUR, B. Reassembling the social. An introduction to actor-network-theory, I ${ }^{a}$ reimpresión, Oxford, Oxford University Press, 2007.

LEMKE, T. «Los riesgos de la seguridad: liberalismo, biopolítica y miedo», Michel Foucault: neoliberalismo y biopolítica, en V. Lemm (ed.), (D. Rosello, trad.), Santiago, Chile, Universidad Diego Portales, 20Io, p. 247-274.

LEWIS, P. «Upskilling the Workers will not Upskill the Work. Why the Dominant Economic Framework Limits Child Poverty Reduction in the UK», Journal of Social Policy, 40, 3, 20II, p. 535-556.

LOBO-GUERRERO, L. «Uberrima fides, foucault and the security of uncertainty», International Journal for the Semiotics of Law(published online I8 april), 2012.

LÓPEZ, I. y RODRÍGUEZ LÓPEZ, E. Fin de ciclo, Madrid, Traficantes de Sueños, 2010.

LUHMANN, N. Risk: a sociological theory (R. Barrett, trans.), I ${ }^{a}$ edición en ingles, New York, Aldine de Gruyter, I993.

MILLAR, J. y RIDGE, T. «Relationship of care: Working lone mothers, their children and employment sustainability», Journal of Social Policy,38(I), 2009, p. I03-I2I.

MORENO MÁRQUEZ, G. Crisis y reconstrucción del Estado del Bienestar: las posibilidades de la Renta Básica de Ciudadanía, Vitoria-Gasteiz: Ed. Servicio Central de Publicaciones del Gobierno Vasco, 2008.

MUNRO, E. Munro, Eileen «Learning to reduce risk in child protection», British Journal of Social Work,40(4), 2OIO, p. II35-II5I.

NAVARRO, V. y REYNOLDS, J. «La inversión en protección social en España en el contexto de la Unión Europea. El reto del déficit social», La situación social en España, en V. Navarro (ed.), Madrid, Biblioteca Nueva y Fundación Largo Caballero, 2009, p. 3I-I36.

O’MALLEY, P. (1992) Risk, power and crime prevention. Economy and Society, 2I(3), I992, 36I-374.

idem; «Risk and responsibility»,Foucault and political reason. Liberalism, neo-liberalism and rationalities of government, en A. Barry, T. Osborne y N. Rose (eds.), London, UCL Press, I996, p. I89-207.

idem; Risk, uncertainty and government, $\mathrm{I}^{\mathrm{a}}$ edición, London, GlassHouse, 2004.

OPITZ, S. «Government unlimited: the security dispositif of illiberal government», Governmentality: current issues and future challenges, en U. Bröckling, S. Krasmann\& T. Lemke (eds.), New York, etc., Routledge, 2OII, p. 93-II4.

OSBORNE, D. y GAEBLER, D. La reinvención del gobierno: La influencia del espíritu empresarial en el sector público, (M. A. Galmarini y F. Pardo Gella, trads.) I I reimpresión en castellano, Barcelona, Paidós Ibérica, I995.

PARTON, N. «Social work, risk and 'the blaming system'», Social theory, social change and social work, en N. Parton (ed.), London; New York: Routledge, I996, p. 98-II4.

PEROTTI, R. «The 'Austerity myth': Gain without pain?», Working Paper, IGIER—Bocconi University, CEPR and NBER, 20II, p. I-57 (disponible en http://www.bis.org/events/confrio623/perotti.pdf; fecha de consulta: I5.II.2OI2).

PITCH, T. «¿Son posibles las políticas democráticas para la seguridad?», Revista Catalana De Seguretat Pública,20, 2009: 29-49.

POWER, M. The Audit society: rituals of verification, I reimpresión, Oxford, Oxford University Press, I999.

PRIETO NAVARRO, E. «Sobre los límites y posibilidades de respuesta jurídica al riesgo», La seguridad en la sociedad del riesgo: un debate abierto, en C. Da Agra, J. L. Domínguez, J. A. García, P. Hebberecht y A. Recasens (eds.), Barcelona, Atelier, 2003, p. 27-46.

PROCACCI, G. «Genealogies of poverty: From inclusion towards exclusion», Development,50(2), 2007, p. 2630. 
RANCIÈRE, J. La noche de los proletarios. archivos del sueño obrero (E. Bernini, trad.), I ${ }^{\mathrm{a}}$ edición en cast., Buenos Aires, Tinta Limón, 2010.

RECASENS, A. «Globalización, riesgo y seguridad: el continuóse de lo que alguien empezóse», La seguridad en la sociedad del riesgo: un debate abierto, en C. Da Agra, J. L. Domínguez, J. A. García, P. Hebberecht y A. Recasens (eds.), Barcelona, Atelier, 2003, p. 365-379.

ídem; La seguridad y sus políticas. $\mathrm{I}^{\mathrm{a}}$ edición, Barcelona, Atelier, 2007.

RIDGE, T. y MILLAR, J. «Following families: Working lone-mother families and their children», Social Policy and Administration,45 (I), 20II, p. 85-97.

ROSE, N. «Authority and the genelogy of subjectivity», Detraditionalization: critical reflections on authority and identity, en P. Heelas, S. Lash \& P. Morris (eds.), Oxford, Blackwell, i996, p. 294-327.

idem; «Government and control», The British Journal of Criminology,40(2), 2000, 32I-339.

idem; Powers of freedom: reframing political thought, $7^{a}$ reimpresión, Cambridge, Cambridge University Press, 2007.

ROSE, N. \&MILLER, P. «Governing economic life», Economy and Society,I9(I), I990, p. I-3I.

idem; «Political power beyond the State: problematics of government», The British Journal of Sociology,43(2), I992, p. I72-205.

ROSE, N.; O’MALLEY, P. y VALVERDE, M. «Governmentality», Annual Review of Law and Social Science,2(I), 2006, p. 83-I04.

SUSÍN BETRÁN, R. La regulación de la pobreza: el tratamiento jurídico-político de la pobreza. Los ingresos mínimos de inserción, I I edición, Logroño, Universidad de La Rioja, Servicio de Publicaciones, 2000.

TAYLOR-GOOBY, P. «Paradigm shifts, power resources and labour market reform», Ideas and welfare state reform in Western Europe, en P. Taylor-Gooby (ed.), Houndmills, Ed. Palgrave Macmillan, 2005, p. I229

TAYLOR-GOOBY, P. Reframing social citizenship, I edición, Oxford, Oxford University Press, 2009.

TEUBNER, G. «The transformation of law in the welfare state», Dilemmas of law in the welfare state, en G. Teubner (ed.), Berlin, etc., Walter de Gruyter, I986, p. 3-I2.

VALVERDE, M. Radicallyrethinkingregulation. Workshopreport. Material no publicado. Instituto Internacional de Sociología Jurídica de Oñati (Guipúzcoa), I994 (fecha de consulta: I4.Io.20Io).

VILA VIÑAS, D. El gobierno de la infancia. Análisis socio-jurídico del control $y$ de las políticas de infancia contemporáneas. Tesis doctoral. Univ. de Zaragoza, 2012.

ZINN, J. O. Social theories of risk and uncertainty: an introduction. $\mathrm{I}^{\mathrm{a}}$ edición, Malden, MA, Blackwell, 2008. 